\title{
Tsunami evacuation modelling as a tool for risk reduction: application to the coastal area of EI Salvador
}

\author{
P. González-Riancho ${ }^{1}$, I. Aguirre-Ayerbe ${ }^{1}$, I. Aniel-Quiroga ${ }^{1}$, S. Abad ${ }^{1}$, M. González ${ }^{1}$, J. Larreynaga ${ }^{3}$, F. Gavidia ${ }^{3}$, \\ O. Q. Gutiérrez ${ }^{1}$, J. A. Álvarez-Gómez ${ }^{2}$, and R. Medina ${ }^{1}$ \\ ${ }^{1}$ Environmental Hydraulics Institute IH Cantabria, Universidad de Cantabria, C/Isabel Torres no. 15, Parque Científico y \\ Tecnológico de Cantabria, 39011 Santander, Spain \\ ${ }^{2}$ Department of Geodynamics, Faculty of Geology, Complutense University of Madrid, C/ José Antonio Novais, s/n, 28040 \\ Madrid, Spain \\ ${ }^{3}$ Ministry of Environment and Natural Resources, Kilómetro 5 1/2 Carretera a Santa Tecla, Calle Las Mercedes, \\ San Salvador, El Salvador
}

Correspondence to: P. González-Riancho (grianchop@unican.es)

Received: 22 April 2013 - Published in Nat. Hazards Earth Syst. Sci. Discuss.: 17 May 2013

Revised: - - Accepted: 18 November 2013 - Published: 13 December 2013

\begin{abstract}
Advances in the understanding and prediction of tsunami impacts allow the development of risk reduction strategies for tsunami-prone areas. This paper presents an integral framework for the formulation of tsunami evacuation plans based on tsunami vulnerability assessment and evacuation modelling. This framework considers (i) the hazard aspects (tsunami flooding characteristics and arrival time), (ii) the characteristics of the exposed area (people, shelters and road network), (iii) the current tsunami warning procedures and timing, (iv) the time needed to evacuate the population, and (v) the identification of measures to improve the evacuation process. The proposed methodological framework aims to bridge between risk assessment and risk management in terms of tsunami evacuation, as it allows for an estimation of the degree of evacuation success of specific management options, as well as for the classification and prioritization of the gathered information, in order to formulate an optimal evacuation plan. The framework has been applied to the El Salvador case study, demonstrating its applicability to sitespecific response times and population characteristics.
\end{abstract}

\section{Introduction}

Tsunamis are relatively infrequent phenomena, but they nonetheless represent an important threat and cause the loss of thousands of human lives and extensive damage to coastal infrastructure around the world (González et al., 2012). Advances in the understanding and prediction of tsunami impacts allow the development of risk reduction strategies for tsunami-prone areas.

Conducting risk assessments is essential to identify the exposed areas and the most vulnerable communities. Hazard, vulnerability and risk assessment results allow the identification of adequate, site-specific and vulnerability-oriented risk management options, with the formulation of a tsunami evacuation plan being one of the main expected results. An evacuation plan requires the analysis of the territory and an evaluation of the relevant elements (hazard, population, evacuation routes, and shelters), the modelling of the evacuation, and the proposal of alternatives for those communities located in areas with limited opportunities for evacuation. This information facilitates the decision-making regarding tsunami risk management.

Several previous works dealing with different aspects of the evacuation process for a tsunami hazard exist. Some authors focus on hazard aspects, such as the calculation of the tsunami wave height, the flooded area, run-up, or arrival time, while others deal with tsunami-related human aspects, such as the calculation of loss of lives, potential casualties, mortality vs. safety, human damage prediction, etc. Some analyse road characteristics as input information for evacuation modelling, while others predict the impacts on buildings using damage functions. Several authors focus on the 
evacuation itself, dealing with the identification of critical areas, the calculation of the evacuation time, or the assessment of warning procedures, among others. Many are oriented to the development of specific evacuation modelling software. Very few authors focus on precisely how to plan a tsunami evacuation. Some examples of the previous works are briefly analysed here.

Regarding the human damage prediction caused by flooding-related disasters, including tsunamis, Sugimoto et al. (2003) presented a tsunami human damage prediction method employing numerical calculation and GIS for a town in a high-risk area. The number of deaths as a result of a tsunami was estimated from the accumulated death toll, taking into account the time necessary to begin to seek refuge after an earthquake, tsunami inundation depth on land, flow velocity and evacuation speed. Jonkman et al. (2008a, b) proposed a method for the estimation of loss of life due to flooding of low-lying areas protected by flood defences, which is given based on the flood characteristics, the exposed population and evacuation, and the mortality amongst the exposed population, using new mortality functions developed by analysing empirical information from historical floods. Koshimura et al. (2006) estimated the number of casualties that may occur while people evacuate from a tsunami inundation zone, based on a simple model of hydrodynamic forces as they affect the human body. The method uses a tsunami casualty index computed at each grid point of a numerical tsunami model to determine locations and times where tsunami evacuation is not possible, and therefore where casualties are most likely to occur. This, combined with population density information, allows for the calculation of the potential number of casualties, which is useful information to identify locations which ought to be excluded from evacuation routes. Sato et al. (2003) proposed a simplified method for tsunami risk assessment without wave run-up analysis, to qualitatively estimate the safety of residents, and examine the effectiveness of tsunami prevention facilities. Two normalized values are evaluated: the ratio of calculated maximum tsunami height to seawall height, and the ratio of the time between tsunami over-topping and evacuation completion to the total time required for evacuation.

Concerning the analysis of specific evacuation issues, Strunz et al. (2011), within the framework of the tsunami risk assessment for the German Indonesian Tsunami Early Warning System (GITEWS), analysed the evacuation of several Indonesian islands, considering vulnerability as the probability of not reaching safe areas in time. Alvear Brito et al. (2009) calculated the population evacuation time through a GIS-based numerical model, in which the critical zones (where the population will not have sufficient time to reach the security areas) are identified by considering factors such as the distance to security zones, the land slope, and accessibility of roads. Clerveaux and Katada (2008) presented a tsunami scenario simulator, which combines the hydrodynamic simulation of tsunamis with warning and human- response simulations for evacuation, mainly focusing on alert communication aspects.

Works on evacuation modelling software may be grouped into three categories, according to the FLOODsite project (HR Wallingford, 2006): (i) traffic simulation models, (ii) evacuation behaviour models, and (iii) timeline/critical path management diagrams. The evacuation modelling shown in this paper fits into the third category. Kolen et al. (2010) described the EvacuAid probabilistic evacuation model, which determines the expected value and bandwidth for the success and loss of life of evacuation strategies based on four parameters: the available time, the behaviour of people, the behaviour of authorities and the available infrastructure and resources. Van Zuilekom et al. (2005) developed the Evacuation Calculator to compute how much time is required for evacuation, and to determine the effect of traffic management during the evacuation process on the required evacuation time. It focuses on traffic flows, and not on individual people or vehicles, and requires data about the average vehicle speed, the capacity of the exit point, the source zones and exits, the distance between them, and the number of people present in each source zone. BC Hydro (2004) developed the Life SafetyModel which allows dynamic interaction between the receptors (e.g. people, vehicles and buildings) and the flood hazard. It requires data about the location of individual properties, vehicles and people, the flood depths and velocities from a two-dimensional hydraulic model, and details of the road network and other pathways. Aboelata and Bowles (2005) proposed the LIFESim model for the estimation of potential loss of life from natural and man-made (dam and levee failure) floods, which comprises three modules: loss of shelter, warning and evacuation, and loss of life.

As far as evacuation planning is concerned, Scheer et al. (2011a), within the framework of the SCHEMA project and the Handbook on Tsunami Evacuation Planning, presented the local tsunami risk assessment and all subsequent implications for evacuation planning, based on the expected tsunami wave height, and the arrival time of the first devastating tsunami wave. This work defines a cost surface layer, evacuation shelter points, a time map, the area covered by each shelter point, the time distance from the closest shelter, the area served by exit/escape points, and the time distance to reach the closest escape point. Scheer et al. (2011b) propose optimizing tsunami evacuation plans through the use of building damage scenarios to identify potential vertical shelters. Garside et al. (2009) state that all at-risk facilities should have appropriate emergency response planning which would include (i) warning notification protocols and systems; (ii) evaluation and mapping of evacuation routes, with signage to designated assembly points; (iii) consideration of evacuation timing; and (iv) staff training and evacuation plan exercising. Besides the existing scientific works, many of the official evacuation plans reviewed (Tokyo's earthquake survival 
manual ${ }^{1}$, Oregon's tsunami evacuation brochures ${ }^{2}$, Chile's tsunami inundation $\mathrm{map}^{3}$, etc.) are oriented to provide citizens from a city/province/country with strategic information such as an evacuation map and some general guidelines about what to do in case of emergency, as opposed to being a tool for decision makers to plan the proper evacuation of the area.

As mentioned above, different partial aspects of tsunami risk and evacuation are addressed in the literature. With a view to the successful planning of the evacuation of the population located in a tsunami prone area, several gaps in the prevailing science are identified: (i) no direct relationship between the specific evacuation-related assessments carried out and the formulation of risk reduction measures and/or an evacuation plan exists, even though some general connections are usually established; (ii) an assessment of the characteristics of the population and communities to be evacuated is not usually undertaken, (iii) the evacuation time is sometimes calculated without considering the tsunami arrival time, resulting in a lack of information regarding the degree of success that the identified evacuation time represents for the population; (iv) an analysis of the time needed by the responsible administrations to issue the tsunami warning and to inform the population is sometimes not considered, although this is essential information for determining the real time available for the population to evacuate; (v) the evacuation modelling results sometimes do not identify, propose or suggest conclusions about how to reduce the risk of the populations identified in critical areas, regarding successful evacuation; and (vi) proposals for improvements in the evacuation process are frequently inadequate, lacking identification of locations to build new vertical shelters and evacuation routes, and omitting warning time reduction strategies, etc.

Based on this analysis, the objective of this paper is to present a framework which aims to eliminate the aboveidentified gaps, providing a global picture of what is required for the adequate formulation of evacuation plans of a study area, and to present evacuation modelling as an essential tool for risk management. This methodological framework proposes an integral approach to considering (i) the hazard aspects (tsunami flooding characteristics and arrival time), (ii) the characteristics of the exposed area (people, shelters and road network), (iii) the current tsunami warning procedures and timing, (iv) the evacuation time needed by the population, and (v) the identification of measures to improve the evacuation. It thus aims to bridge the gap between risk assessment and management in tsunami evacuation. Finally, an application of this framework to the

\footnotetext{
${ }^{1}$ Tokyo Metropolitan Government: Earthquake survival manual

${ }^{2}$ Oregon Department of Emergency Management and Oregon Department of Geology and Mineral Industries: Tsunami Evacuation Brochures

${ }^{3}$ Gobierno de Chile: Carta de Inundación Por Tsunami, Zona Urbana Coronel Costa (in Spanish)
}

coastal area of El Salvador, and specifically to the Western Coastal Plain, is presented in this paper along with a discussion on the major findings.

\section{Framework for tsunami evacuation planning}

Evacuation plans, which are developed by the responsible authorities and decision makers, would benefit from a clear and straightforward connection between the scientific and technical information from tsunami risk assessments and the subsequent risk reduction options. Scientifically-based evacuation plans would translate into benefits for the society in terms of mortality reduction. Figure 1 shows the methodological framework proposed for evacuation planning, which is divided into three phases: analysis, modelling and planning. This framework and its three phases are intended to be supported by participatory processes involving the local communities, the Civil Protection, emergency-related NGOs and responsible authorities, among others. These processes aim to (i) inform the stakeholders about the work, (ii) involve them in the overall evacuation planning process, from the preliminary designs to the validation of the evacuation strategy and maps, (iii) include their knowledge in the analysis, and (iv) thereby improve the final planning results.

The analysis phase aims to examine the territory and communities exposed to the tsunami flooding in order to identify critical elements from the point of view of the evacuation, by examining the characteristics of the population, the characteristics of the road network and the availability of safe areas in case of tsunami events. These three components (population, routes and shelters) are identified and weighted based on several evacuation-relevant criteria (reaction time, travel speed and isolation of the exposed population; travel difficulty and safety of the road network; and capacity, safety and accessibility of shelters), to obtain essential information for the preparation of a preliminary evacuation proposal that distributes the population among the different shelters identified. This preliminary proposal is intended to then be discussed and reviewed with the exposed local communities in order to include and benefit from their experience, perception and knowledge.

The modelling phase aims to refine and update the preliminary evacuation proposal to identify the critical areas that would not be able to be evacuated and that should therefore be priority candidates for risk reduction measures. The evacuation modelling considers the distances to be travelled and the evacuation speeds of the population, the tsunami arrival time and the current risk management procedures, such as the warning time needed by the responsible authorities and the reaction time of the population. This information is best obtained through consultations with the involvement of the responsible authorities, in order to include their experience and knowledge about existing warning protocols and the main difficulties faced in emergency events. Once the critical areas 


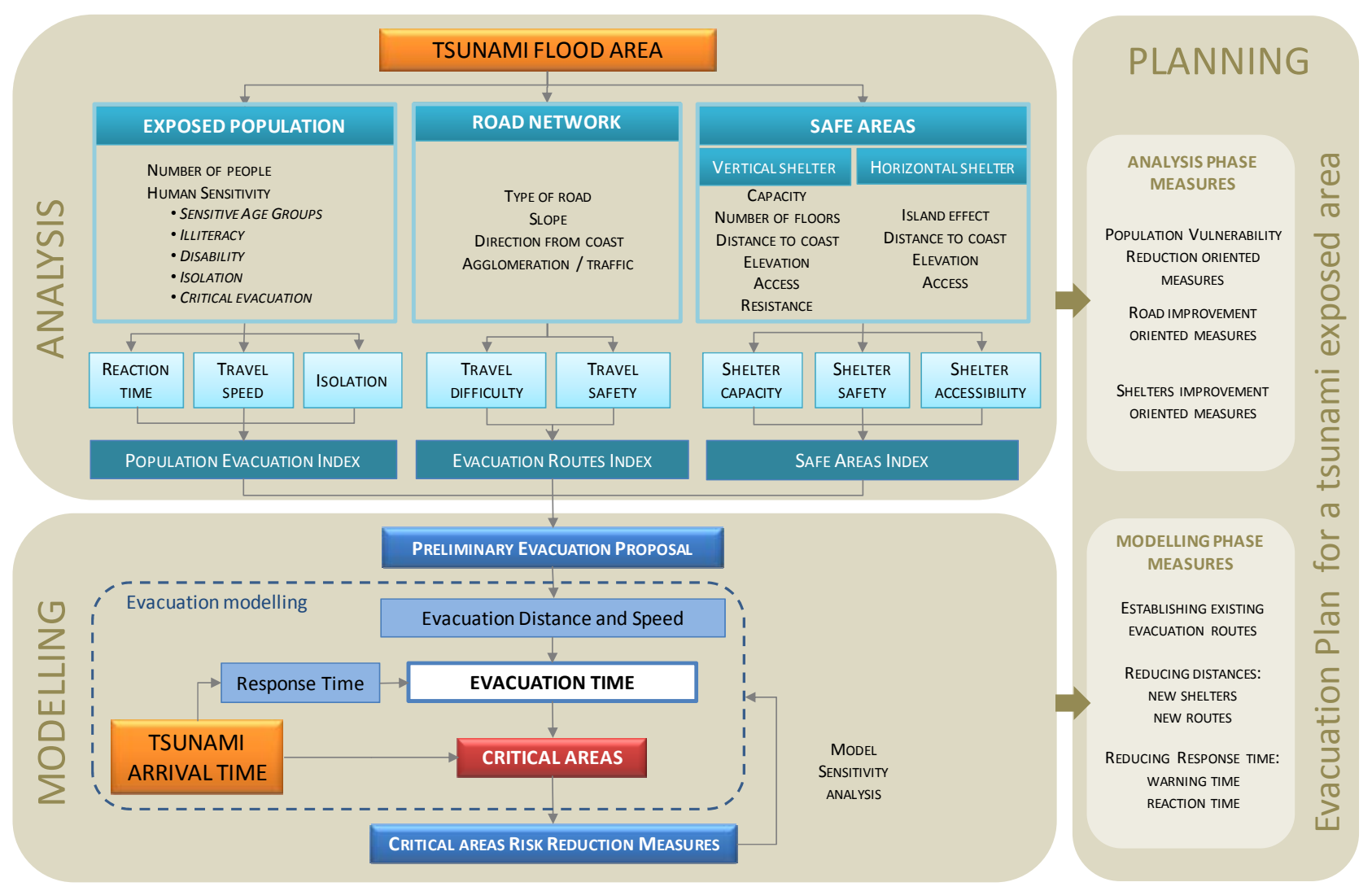

Fig. 1. Tsunami evacuation planning framework.

have been identified, alternatives dealing with reducing the distances to be travelled and/or increasing the available time are proposed to reduce risk. These proposals are also modelled to ensure that the critical areas are gradually reduced, and this process is repeated until these areas are eliminated.

The planning phase aims to gather all the information produced in the analysis and modelling phases as inputs for a comprehensive tsunami evacuation plan. The analysis of the exposed population will result in measures to ensure the proper evacuation of the entire population, by reducing the limitations produced by the reaction time, the travel speed and the isolation of communities. Analysis of the road network and safe areas will result in measures to improve both elements, by increasing the capacity, safety and accessibility of roads and shelters. The evacuation modelling will provide conclusions about the need for reducing (i) the distances that the population has to travel until they reach a safe area, (ii) the authorities' response time (detection, analysis and warning time) and (iii) the population reaction time, and consequently the measures are oriented to these issues. This framework permits interactive and adaptive planning and management, as once the above-mentioned measures have been implemented, the three evacuation indices (population evacua- tion index, evacuation routes index and safe areas index) will be improved towards their optimal status.

Based on this framework, the chapter is divided into six sections: (1) identification of the potential tsunami-flooded area, (2) analysis of the exposed population, safe areas and evacuation routes, (3) time calculation, (4) evacuation modelling, (5) proposal of alternatives for critical areas, and (6) evacuation planning.

\subsection{Identification of the potential tsunami-flooded area}

A proper identification of the potential tsunami-flooded area requires a hazard assessment based on tsunami propagation models through the characterization of tsunamigenic sources and other oceanic and coastal dynamics. Simulations of historical and potential tsunamis with variable impact on the coast should be performed including distant, regional and local sources. Probabilistic or deterministic analyses can be carried out to generate different hazard maps such as the maximum wave height elevation, the maximum water depth, the maximum flooding level or run-up, the minimum tsunami arrival time, and the maximum potential drag, understood as the hazard degree for human instability based on incipient water velocity and depth. 
A specific methodology for the hazard assessment is not detailed in this section, as this paper focuses on evacuation planning. For further methodological information see Álvarez-Gómez et al. (2013).

\subsection{Analysis of the exposed population, safe areas and road network}

Once the potential tsunami-flooded area has been identified and consequently the exposed communities and infrastructures are known and geographically located, a characterization of the exposed population, the safe (not-flooded) areas and the road network to reach these areas is performed.

The analysis of the exposed population in terms of evacuation is based on the population evacuation index (PEI) and a series of evacuation indices and indicators. For the calculation of the PEI, (i) the reaction time index considers the number of illiterate people (related to not understanding a warning message) and the number of people located in critical buildings, understood as those that house large numbers of people to be organized jointly in case of evacuation (hospitals, schools); (ii) the travel speed index is based on the number of disabled and sensitive age people (children and the elderly); and (ii) the isolation index considers the expected number of people that may have difficulties evacuating due to the characteristics of their territory. In conclusion, gathering knowledge about the number of people to be evacuated, their location and their characteristics and limitations regarding evacuation, is extremely useful to successfully manage their evacuation and to foster their preparedness in a specificityoriented manner.

Evacuation to safe areas distinguishes between horizontal and vertical shelters. Horizontal evacuation refers to the strategy for arriving in the areas that are not flooded which are outside the hazard zone or on accessible high grounds. Vertical evacuation refers to the strategy for escaping within the hazard zone by going up to higher floors in buildings or other artificial structures. Tsunami numerical modelling defines the potentially flooded area, which then permits the establishment of horizontal security zoning. The security zoning is proposed to be comprised of the following zones:

- Tsunami-flooded area: area with larger flood depths and flow velocities near the coast and lower depths and flow velocities further inland. Evacuation from this area is strongly recommended.

- Medium-security area: this zone is established between the maximum flood level in the study area and a security level specifically determined for each zone and defined by elevation. This area would be the minimum evacuation objective to be achieved by the population in order to ensure their safety.

- High-security area: from the medium-security zone onwards. This area is the evacuation objective for those located in the medium-security zone when the alert is received and for anyone able to reach this area in the available time.

Potential vertical shelters located within the tsunami hazard area are identified, analysed and prioritized based on the above-shown criteria, i.e. capacity, safety and accessibility. The current road network is also analysed to identify the existing evacuation routes in the study area, and to select those roads that connect populated areas with medium-security areas and prioritized in terms of ease of travel and safety.

The set of indicators proposed for the analysis of the exposed people, road network and safe areas is shown in Table 1, with several mathematical-statistical procedures being applied to them in order to generate comparable and combinable information. The following paragraphs describe the methodology used to integrate the indicators.

The indicators proposed for the assessment of the exposed population, road network and safe areas help in (i) identifying specific weaknesses to be addressed within a tsunami preparedness program, and (ii) prioritizing routes and shelters. The indicators for the assessment of safe areas also provide, through the binary indicators, information used to reject some shelters from the planning process (for example, nonresistant vertical shelters, island effects on horizontal shelters, and no available access to either kind of shelter results in a direct rejection).

Following OECD/EC-JRC (2008), the process for the integration of the evacuation indicators and indices has the following steps: (i) building indicators through normalization; (ii) building indices through weighted aggregation, and (iii) indices classification through the natural breaks method. The transformation of the variables range of values is carried out using the minimum-maximum (Min-Max) method, which normalizes the indicators to an identical range $[0,1]$ by subtracting the minimum value and dividing by the range of the indicator values. The indices are built through the weighted aggregation of the normalized indicators, the weights being associated with (i) the importance it represents for the index to which it belongs, and (ii) the reliability of the information (for example, although the type of road - in terms of materials, width and conservation - is considered important for an efficient evacuation, it is common to find that a high percentage of the roads that must be used are not the best type of roads, therefore in such cases this indicator should be lowweighted). The partial indices obtained are also weighted and aggregated to build the composite index. The indices are classified and translated into 5 classes, this ranking being linked to a colour code to represent the information geographically. The Natural Breaks classification method, based on the Jenk's optimization algorithm, implemented in the ArcGIS $^{\circledR}$ software and designed to determine the best arrangement of values into different classes is applied. The method reduces the variance within classes and maximizes the variance between classes (Jenks, 1967) by minimizing 
Table 1. Set of indices and indicators for the analysis of exposed population, road network and safe areas $(V=$ vertical shelter; $H=$ horizontal shelter).

\begin{tabular}{|c|c|c|c|}
\hline $\begin{array}{l}\text { Composite } \\
\text { indices }\end{array}$ & Indices & Indicators & Variables \\
\hline \multirow{5}{*}{ 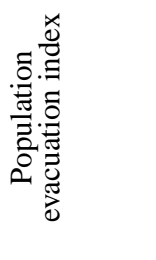 } & \multirow[t]{2}{*}{ Reaction time } & Illiteracy & Number of illiterate people \\
\hline & & Critical evacuation & Number of people in critical buildings \\
\hline & \multirow[t]{2}{*}{ Travel speed } & Sensitive age groups & Number of people below $10 \mathrm{yr}$, and above $65 \mathrm{yr}$ \\
\hline & & Disability & Number of people with physical/intellectual disability \\
\hline & Isolation & Isolation & Number of people located in isolated areas \\
\hline \multirow{4}{*}{ 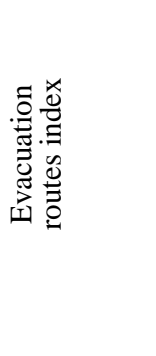 } & \multirow{3}{*}{ Travel difficulty } & Type of road & $\begin{array}{l}\text { Number of road segments (per evacuation route) below a predefined } \\
\text { site-specific level of quality }\end{array}$ \\
\hline & & Slope & $\begin{array}{l}\text { Number of road segments (per evacuation route) with more than } \\
9 \% \text { slope (based on Cano et al., } 2011 \text { and Laghi et al., 2006) }\end{array}$ \\
\hline & & Agglomeration/traffic & $\begin{array}{l}\text { Number of road segments (per evacuation route) with common } \\
\text { agglomeration/traffic bottlenecks }\end{array}$ \\
\hline & Travel safety & Direction from the coast & $\begin{array}{l}\text { Number of road segments (per evacuation route) } \\
\text { and distances to travel parallel to the coast }\end{array}$ \\
\hline \multirow{7}{*}{ 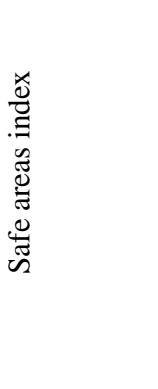 } & Shelter capacity & Capacity $(V)$ & Number of people that can be hosted per vertical shelter \\
\hline & \multirow{5}{*}{ Shelter safety } & Number of floors $(V)$ & Number of floors per vertical shelter \\
\hline & & Resistance $(V)$ & Materials resistance per vertical shelter (yes/no) \\
\hline & & Distance to the coast $(V / H)$ & Distance $(\mathrm{m})$ from the shelter to the coast \\
\hline & & Elevation $(V / H)$ & Elevation $(m)$ from the sea level per shelter \\
\hline & & Island effect $(H)$ & Horizontal safe area surrounded by flooding (yes/no) \\
\hline & $\begin{array}{l}\text { Shelter } \\
\text { accessibility }\end{array}$ & $\operatorname{Access}(V / H)$ & Open access to the shelter by road (yes/no) \\
\hline
\end{tabular}

each class's average deviation from the class mean, while maximizing each class's deviation from the means of the other groups. It has been selected after testing other methods (such as the equal interval, defined interval, quantile, geometrical interval, standard deviation, etc.), as it permits grouping within the same class the planning units (e.g. municipalities) that have similar values, i.e. that behave in the same way and which are expected to need similar measures. Since this method of classification depends on the distribution of the data, the study of any index evolution over time must maintain the ranges established in the initial analysis (González-Riancho et al., 2013).

\subsection{Time calculation}

Some time-related concepts essential to understanding the study are as follows (Fig. 2):

- Tsunami arrival time $\left(T_{\text {Tsunami }}\right)$ : time from the tsunami generation until the first wave arrives at the coastal area. The tsunami arrival time map is represented by time contour lines and a colour code.
- Total evacuation time: time from the tsunami generation until the entire population reaches a safe area. It consists of two concepts:

a. Response time ( $\left.T_{\text {Response }}\right)$ : time from the tsunami generation until the population begins to evacuate. This time includes:

i. Detection and warning time: time from the earthquake detection and the analysis of its characteristics until the tsunami warning is issued by the responsible authority.

ii. Alert transmission time: time from the reception of the alert by the intermediate authorities in charge of crisis management (such as Civil Protection) at the national level and its transmission to those responsible at the local level.

iii. Alert reception time: time from the reception of the alert by those responsible at the local level until the entire community is informed.

iv. Population reaction time: time elapsed from the instant the population receives the alert until they start to evacuate. 


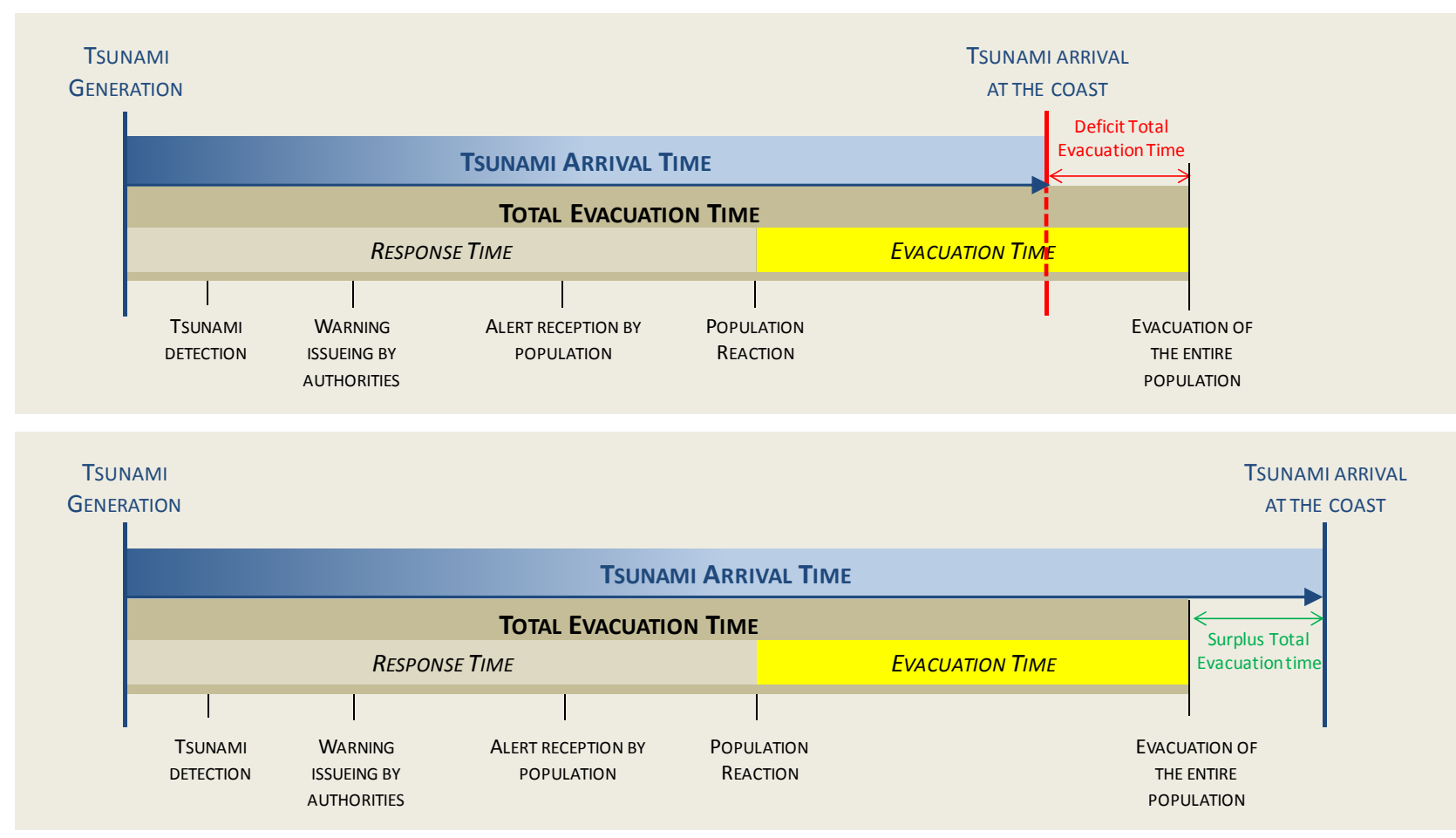

Fig. 2. Tsunami evacuation timelines: to ensure the evacuation of the entire exposed population, the Total Evacuation Time - TET -, which includes the response and the evacuation times, must be lower than the time the tsunami needs to arrive at the coast (Surplus TET, image below). The opposite situation (Deficit TET, image above) implies potential human impacts.

b. Evacuation time $\left(T_{\text {Evacuation }}\right)$ : time from the beginning of the evacuation until the population arrives in a safe zone (walking evacuation time).

The tsunami arrival time is calculated based on the hazard assessment described in Sect. 2.1 by means of the generation of a set of tsunami arrival time maps through numerical modelling. The response time can be obtained from the existing emergency protocols or from direct work with the responsible authorities, at least the information regarding the detection and warning, alert transmission and reception times. The reaction time of the population, if no information is available, may be assumed to be $15 \mathrm{~min}$ for prepared/aware people, based on Post et al. (2009) and Strunz et al. (2011), despite being a simplification, as not the whole population would evacuate at the same time. The evacuation time is to be obtained from the evacuation modelling considering the tsunami arrival time and response time.

A deficit in the total evacuation time is generated when the time needed for evacuation is greater than the time the tsunami takes to arrive at the coast. A surplus is obtained when the opposite situation happens (see Fig. 2). As the tsunami arrival time cannot be controlled, the only option to reduce the risk for coastal communities depends on the management (reduction) of the response and evacuation time. The evacuation time depends on the distances to be travelled and the population speeds; assuming that no improvements to evacuation time (such as building new shorter routes, organizing specific help for slow populations, etc.) can be implemented at the moment, then the current evacuation success will mainly depend on the response time: the lower the response time, the more time will be available for the evacuation and to reach a safe area before the first tsunami wave arrives. The evacuation corresponding to various response times should be analysed and modelled in order to identify the critical one for which the population would not be able to evacuate in time.

\subsection{Evacuation modelling}

An evacuation modelling is carried out to identify optimal evacuation routes and the time needed for the population to evacuate, based on the tsunami arrival time, the security zoning and the road network. For the evacuation modelling applied within the framework proposed in this paper, the network analyst extension of the ArcGIS ${ }^{\circledR} 10.1$ software is used to create a network database and perform various analyses considering the definition of attributes and connectivity standards. Based on this extension, the "closest facility" analysis is applied to measure the travelling cost between origin and destination points. The following factors are considered for modelling: 
- Evacuation distances: the aim is to obtain the minimum distance a person has to walk $(L)$ from each evacuation point of origin (located at every road intersection inside the flooded area and based on the spatial analysis of the distribution of population) to the destination point (located where each road gets out of the flood sheet).

- Evacuation speed ( $V$ ): based on Sugimoto et al. (2003) and Mück (2008), two types of people with different speeds $(V 1, V 2)$ are considered:

i. Fast population, generally associated with adults, with an evacuation speed of $V 1=1 \mathrm{~m} \mathrm{~s}^{-1}$.

ii. Slow population, associated with the elderly, children and the disabled, with an evacuation speed of $V 2=0.7 \mathrm{~m} \mathrm{~s}^{-1}$.

- Evacuation time ( $\left.T_{\text {Evacuation }}\right)$ : the time needed to travel the length $L$ to the safe area (destination point); it depends on the different speeds considered ( $T_{\text {Evacuation } 1 \text {, }}$ $T_{\text {Evacuation2): }}$

i. Fast population: $T_{\text {Evacuation } 1}=L / V 1$.

ii. Slow population: $T_{\text {Evacuation } 2}=L / V 2$.

- A slope slows the evacuation (slope $=(\mathrm{Za}-\mathrm{Zo}) / L$; $\mathrm{Za}$ being the highest point and Zo the lowest point on the evacuation route). Thus, according to Laghi et al. (2006) and Cano (2011), speeds are corrected based on the slope (see Table 2), and consequently the evacuation times are also corrected. The slope calculation considers the difference of elevation between the origin and destination points, assuming that the latter points are always located on higher ground.

- Response time $\left(T_{\text {Response }}\right)=$ time from the occurrence of the tsunamigenic event until the population begins to evacuate

- Total evacuation time $(T)$ for each type of population by speeds $(T 1, T 2)$ :
i. Fast population: $T 1=T_{\text {Response }}+T_{\text {Evacuation1 }}$.
ii. Slow population: $T 2=T_{\text {Response }}+T_{\text {Evacuation2 } 2}$.

According to the response time modelled in each case, the model provides the shortest path from each origin point to the destination point, calculates the time required for walking the shortest path identified, and colours the origin point depending on the result obtained. Table 3 shows the colour code used to represent these results, depending on whether the total evacuation time of the fast population $(T 1)$ and the slow population $(T 2)$ are less than or greater than the tsunami arrival time $\left(T_{\text {Tsunami }}\right)$.

As the number of exposed people is known, this modelling also permits the calculation of the evacuation balance, understood as the percentage of people getting evacuated by
Table 2. Evacuation speed correction based on the slope (Laghi et al., 2006).

\begin{tabular}{rr}
\hline Slope (\%) & Speed value \\
\hline $0-3$ & $100 \%$ \\
$3-6$ & $85 \%$ \\
$6-9$ & $70 \%$ \\
$9-12$ & $55 \%$ \\
$12-5$ & $45 \%$ \\
$15-18$ & $40 \%$ \\
$18-21$ & $35 \%$ \\
$21-24$ & $30 \%$ \\
$24-27$ & $25 \%$ \\
$27-30$ & $20 \%$ \\
$30-33$ & $15 \%$ \\
$33-36$ & $14 \%$ \\
$36-39$ & $13 \%$ \\
$39-42$ & $12 \%$ \\
$42-45$ & $11 \%$ \\
45 or more & $10 \%$ \\
\hline
\end{tabular}

census tract for the response time analysed. The evacuation balance depends on both the distance to be travelled and the population speed.

\subsection{Proposal of alternatives for critical areas: a sensitivity analysis of the evacuation model}

Depending on the evacuation results obtained for a specific response time, the formulation of particular measures to improve the evacuation of the area may be required. These measures can be of two types:

- The reduction in the response time, which would increase the time available for evacuation.

- The reduction in the distance to be travelled by communities which are currently not able to evacuate in time, by means of building vertical evacuation shelters and/or new evacuation routes.

After the proposals for alternatives to reduce the response time and/or the distances to be travelled are implemented, the evacuation shall be modelled again in order to confirm that the critical area is being reduced and that more of the population is being evacuated. Further measures should be applied and modelled until the entire area evacuates successfully. This sensitivity analysis of the evacuation model represents a powerful tool for managers to reduce the risk of specific areas, by ensuring the successful evacuation of the population, as it allows for the prediction and assessment of the results of specific management options.

Regarding the identification of possible locations for vertical evacuation shelters in the study areas, once a lower (than the initial) response time is modelled and the critical areas have been identified, the following steps are required: 
Table 3. Results for the relationships between tsunami arrival time and total evacuation time.

\begin{tabular}{|c|c|c|c|c|}
\hline & $\begin{array}{r}\text { Total Evacuatio } \\
\text { Fast population } T 1\end{array}$ & $\begin{array}{l}\text { Time }(T 1<T 2) \\
\text { Slow population } T 2\end{array}$ & Result & $\begin{array}{l}\text { Colour code } \\
\text { (evacuation } \\
\text { origin points) }\end{array}$ \\
\hline \multirow{3}{*}{ 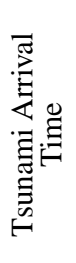 } & $T 1>T_{\text {Tsunami }}$ & $T 2>T_{\text {Tsunami }}$ & $\begin{array}{l}\text { No one starting from this } \\
\text { origin point would evacuate }\end{array}$ & Red \\
\hline & $T 1<T_{\text {Tsunami }}$ & $T 2>T_{\text {Tsunami }}$ & $\begin{array}{l}\text { Only the fast population } \\
\text { group would evacuate }\end{array}$ & Orange \\
\hline & & $T 2<T_{\text {Tsunami }}$ & $\begin{array}{l}\text { Everyone starting from this } \\
\text { originpoint would evacuate }\end{array}$ & Green \\
\hline
\end{tabular}

i. Identification of areas where the population that would be unable to evacuate for this lower response time ( $T_{\text {Response }}$ ) is concentrated (the selection of the initial response time and subsequent reductions to model is context-specific and depends on the modelled tsunami arrival time and the minimum potential response time for the case study).

ii. Location of towers at strategic points in that area. Designers must select the initial location of towers based on the following information: the number and distribution of people along the flooded area with special attention to the people located seaward of the shelter, the tsunami arrival time at the coastline, the geomorphologic characteristics of the territory and the subsequent effects on the tsunami.

iii. Calculation of the arrival time of the tsunami $\left(T_{\text {Tsunami }}\right)$ at each tower. Assuming that a warning will be issued -the modelling is based on a predefined response time, the arrival time at the tower is calculated in order to understand the available time to reach it. Knowing the tsunami arrival time at the coast and the location of the various communities, the selection of the tower location must ensure that the tsunami arrival time at the tower is higher than the added reaction and evacuation times of the population located seaward to the shelter.

iv. Calculation of the time available for evacuation at that point, i.e. the time that people have to arrive at the tower before it is reached by the first tsunami wave $\left(T_{\text {Evacuation }}=T_{\text {Tsunami }}-T_{\text {Response }}\right)$.

v. Calculation of the distance that can be travelled for that evacuation time for the two considered speeds $\left(V 1=\mathrm{m} \mathrm{s}^{-1}, V 2=0.7 \mathrm{~m} \mathrm{~s}^{-1}\right)$.

vi. Modification of tower locations, based on the obtained results for each tower, i.e. the initial position is maintained or modified to improve results in terms of number of people reaching the shelter. Any improvement implies going back to steps iii, iv, $v$ and vi until the final location satisfies designer.
Note that in this work, this iterative procedure has been performed heuristically and based on designer experience. However, the methodology could be settled like a mathematical programming problem and solved by standard optimization procedures. The tower locations and its number would be the optimization or decision variables, and the problem could be stated in two different forms: (i) minimize the tower costs subject to the constraint that all inhabitants would have time enough to reach shelter on time; this case assumes that there are no budget limitations; or (ii) maximize the number of people reaching shelter on time, constraint by a limited budget. Although the first option is preferable, reality makes the second option most likely. This automatic selection of the number and location of towers is a subject for further research.

In spite of how this selection if performed, at the end of the process the following information (Fig. 3) is provided for each tower: the tsunami arrival time $\left(T_{\text {Tsunami }}\right)$; the response time ( $\left.T_{\text {Response }}\right)$; the time available to evacuate ( $\left.T_{\text {Evacuation }}\right)$; and the reception distance for both population speeds, which is represented by the green and red concentric rings surrounding the towers (the population located in the green ring would reach the tower in the available time, regardless of whether they belong to the fast or slow population; from the population located in the red ring only the fast population would reach the tower in time).

\subsection{Evacuation planning}

The above-described process provides essential information for tsunami risk management, including the formulation of an evacuation plan. The analysis phase provides measures oriented to (i) reducing the limitations of populations in terms of evacuation, (ii) improving the road network and (ii) improving the existing shelters; while the modelling phase offers measures oriented to (iv) the reduction of current evacuation distances to be travelled and (v) reducing the current response time. Based on this, Table 4 presents an example of an evacuation plan structure and measures. 
Table 4. Evacuation plan structure.

\begin{tabular}{|c|c|c|}
\hline $\begin{array}{l}\text { General } \\
\text { objectives }\end{array}$ & $\begin{array}{l}\text { Specific } \\
\text { objectives }\end{array}$ & Examples of measures \\
\hline 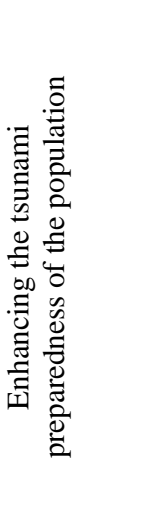 & 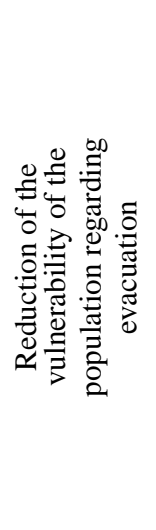 & $\begin{array}{l}\text { Reaction time measures } \\
\text { - Information, awareness, capacity building and specific help for people who } \\
\text { have difficulties understanding a warning message } \\
\text { - Specific evacuation training for critical buildings staff (schools, } \\
\text { geriatrics, hospitals, etc.) } \\
\text { Travel speed measures } \\
\text { - Information, awareness and capacity building for slow groups (elderly, } \\
\text { disabled, pregnant women and children) } \\
\text { - Community organization and specific help for slow groups } \\
\text { Isolation measures } \\
\text { - Information, awareness and training for isolated areas } \\
\text { - Specific help (transport services) for isolated areas } \\
\text { - Warning time prioritization to isolated areas }\end{array}$ \\
\hline 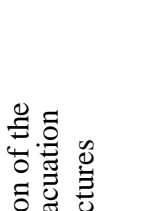 & 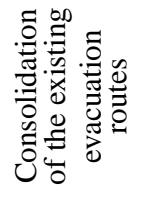 & $\begin{array}{l}\text { Travel difficulty measures } \\
-\quad \text { Urban traffic management to avoid bottleneck areas } \\
\text { - Removal of potential bottlenecks (i.e. markets) from evacuation routes } \\
\text { Travel safety measures } \\
\text { - Improve/fix existing roads to facilitate the evacuation }\end{array}$ \\
\hline 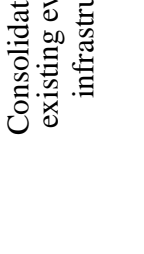 & 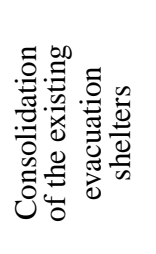 & $\begin{array}{l}\text { Shelter capacity measures } \\
\quad-\quad \text { Increasing the capacity of certain shelters when possible } \\
\text { Shelter safety measures } \\
\quad-\quad \text { Structural reinforcement of existing structures } \\
\text { Shelter accessibility measures } \\
\quad-\quad \text { Improve accessibility to existing shelters, eliminate barriers to evacuation }\end{array}$ \\
\hline 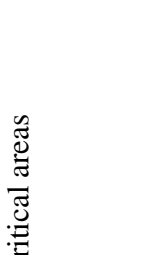 & 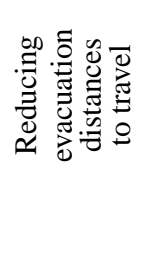 & $\begin{array}{l}\text { Building new routes } \\
-\quad \text { Building new routes to shorten the current evacuation distances } \\
\text { Building new shelters } \\
-\quad \text { Building new shelters to shorten the distances to travel by the } \\
\text { communities that currently are not able to evacuate } \\
-\quad \text { Special help for the slow population located on the red ring }\end{array}$ \\
\hline 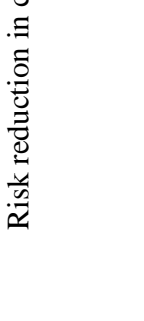 & 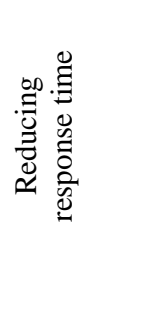 & $\begin{array}{l}\text { Reducing warning time } \\
- \text { Early warning system } \\
\text { - Capacity building in critical areas } \\
\text { - Optimization of communication system: networking, technology, } \\
\text { mobile, tsunami warning speakers, etc. } \\
\text { Reducing reaction time } \\
\text { - Information and awareness campaigns in critical areas } \\
\text { - Training, evacuation drills in critical areas }\end{array}$ \\
\hline
\end{tabular}

\section{Application to the coastal area of El Salvador}

This chapter presents the application of the described methodological framework for evacuation planning to the coastal area of El Salvador. Of the tsunamis that have hit the Pacific coast of Central America, only 4 have been generated by distant sources (including the two recent tsunamis of Chile 2010 and Japan 2011) versus 30 local events, 7 of which were damaging (Álvarez-Gómez et al., 2012). Ac- cording to Álvarez-Gómez et al. (2012), MARN (2009), Fernández et al. $(2004,2000)$ and Fernández (2002), the study area is located in an area of high seismic activity which has been hit by 15 tsunamis between 1859 and 2012 (Fig. 4 and Table 5), with all of them having been generated by earthquakes, and two of them being highly destructive; one in 1902 that affected the eastern coast of the country and one in 1957 that affected Acajutla. The most recent, albeit of lesser 


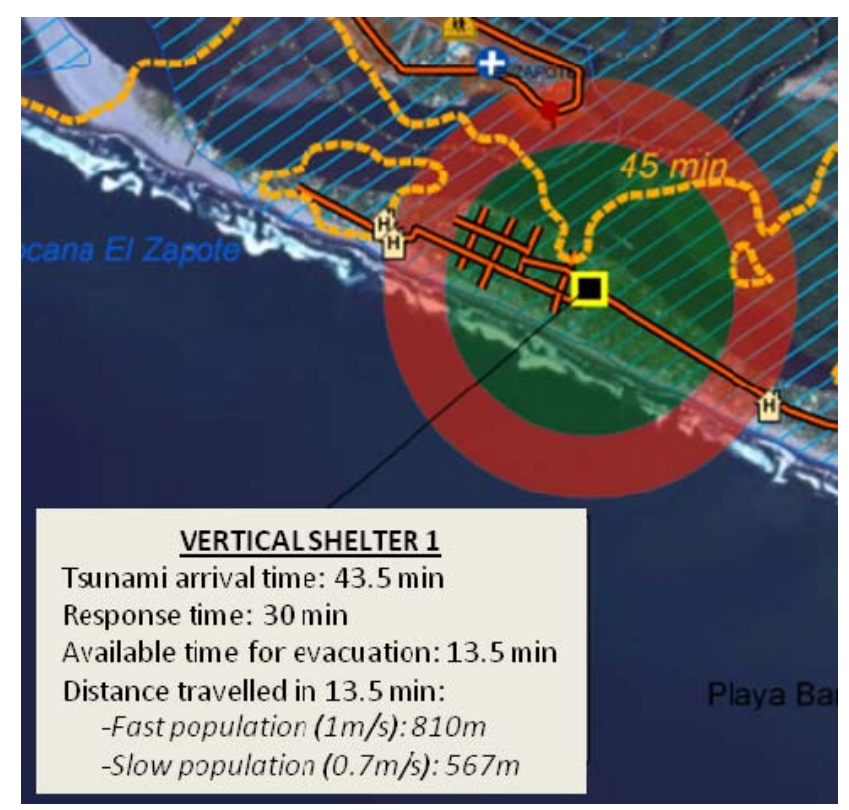

Fig. 3. Example of the information provided for a vertical evacuation shelter.

magnitude, occurred in August 2012, affecting Jiquilisco Bay (IH Cantabria-MARN, 2012).

The work presented here is framed within a comprehensive methodology for assessing the tsunami risk in coastal areas worldwide, and applied specifically to the coast of El Salvador during the period 2009-2012. Two spatial scales have been applied for the risk assessment in the project, a global analysis for the national scale, and a local and more detailed analysis for three specific areas at higher risk: the Western Coastal Plain, La Libertad and the Bahía de Jiquilisco. Evacuation has been modelled for the three local studies. The results obtained for the Western Coastal Plain are presented in this paper.

\subsection{Identification of the tsunami-flooded area}

The hazard assessment is based on propagation models for earthquake-generated tsunamis, developed through the characterization of tsunamigenic sources - seismotectonic faults - and other dynamics (waves, sea level, etc.). Simulations of historical and potential tsunamis that affect the coast to a greater or lesser extent have been performed, including distant sources (distances greater than $2000 \mathrm{~km}$ to the coast, with tsunami travel times greater than $4 \mathrm{~h}$ ), regional sources (between 700 and $2000 \mathrm{~km}$ with tsunami travel times between 1 and $4 \mathrm{~h}$ ), and local sources (located in the subduction trench off the country's coast with tsunami travel times of less than $1 \mathrm{~h}$ ).

A deterministic analysis (aggregated analysis that combines the 23 worst credible cases of tsunamis that could impact on the Salvadoran coast, see Fig. 5) has been carried out, considering local seismic sources located in the Middle America Trench, characterized seismotectonically, and distant sources in the rest of Pacific Basin, using historical and recent earthquakes and tsunamis. The earthquakes magnitude ranges between $\mathrm{Mw} 7.7$ for some local sources and $\mathrm{Mw} 9.5$ for distant sources (Álvarez-Gómez et al., 2013). According to the methodology proposed by the SCHEMA project (Tinti et al., 2011), when applying the worst-case credible scenario approach to the tsunami hazard assessment the process of aggregation of the results obtained for the single tsunami sources consists in selecting for each position of the map the extreme value (the highest or the lowest) computed for the individual cases. The main outputs (Fig. 6) are different hazard maps (maximum wave height elevation, maximum water depth, maximum flow velocity, minimum tsunami arrival time, maximum flooding level or "run-up", and maximum potential drag along the coast of El Salvador and at some relevant locations with high resolution analysis. Further information on this deterministic hazard assessment is provided by Álvarez-Gómez et al. (2013).

For evacuation analysis purposes the drag hazard map has been used, as it allows understanding the potential human instability based on incipient water velocity and depth to better explain the human risk caused by the tsunami. Regarding the drag calculation, the drag value at each point of the grid and for each event modelled is obtained by multiplying the flow velocity $(u)$ value by the flow depth $(h)$ value at each instant, and calculating the maximum value of the product, i.e. $\max (h \times u)$, which is different than considering the maximum value of the velocity at that point (i.e. $\max (u) \times h)$. The drag value at each point of the grid for the aggregated case is the maximum drag value obtained among the 23 events.

\subsection{Analysis of exposed population, safe areas and road network}

The analysis of the exposed population in terms of evacuation has been carried out using the exposure and vulnerability information gathered for the tsunami risk assessment (González-Riancho et al., 2013), with the census tract being the analysis unit at the local level. Based on the methodology presented in Sect. 2 and a geographic information system, several partial and aggregated maps have been generated to better understand the population evacuation index (PEI). Figure 7 shows the PEI map, together with the three indices composing it: (i) the reaction time index of each census tract exposed to the hazard has been calculated, aggregating the number of illiterate people and the number of people located in critical buildings, including schools, hospitals, health centres, hotels, geriatrics, churches, malls, sports and leisure centres; (ii) the travel speed index is based on the number of disabled persons, as well as children below $10 \mathrm{yr}$ and persons above $65 \mathrm{yr}$; and (iii) the isolation index considers the number of people located in badly connected road areas, or those that frequently get isolated due to other extreme events 

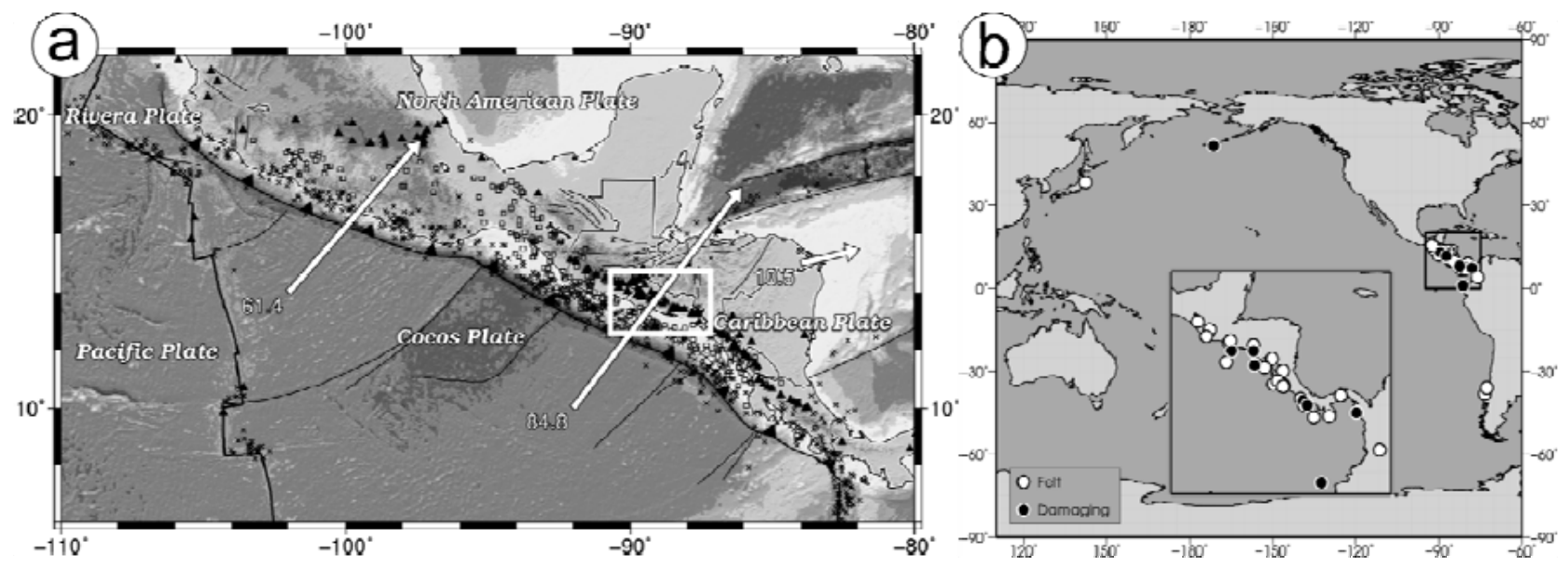

Fig. 4. Location of El Salvador, fault zones and epicentres of past earthquakes (figure and caption modified from Álvarez-Gómez, 2012). (a) Tectonic setting of the Middle America Trench. The white square shows the location of El Salvador; the arrows illustrate the direction and magnitude of the plate motions taking the North American Plate; the label is the motion magnitude in mm/year; the triangles show the position of the Holocene volcanoes; cross symbols represent the shallow seismicity (b50 km) and squares the rest of the seismic Global CMT Catalog. (b) Tsunami catalog of the pacific coast of Central America; white circles: epicentres of non-destructive tsunamis; black circles: epicentres of damaging tsunamis.

Table 5. Catalogue of historical tsunamis affecting the coast of El Salvador. Data from MARN (2009), Fernández (2002) and USGS Earthquake Hazards Program (http://earthquake.usgs.gov).

\begin{tabular}{|c|c|c|c|c|}
\hline Date & Country & $\begin{array}{l}\text { Earthquake } \\
\text { location }\end{array}$ & $\begin{array}{l}\text { Earthquake } \\
\text { magnitude }\end{array}$ & $\begin{array}{l}\text { Tsunami impact } \\
\text { location }\end{array}$ \\
\hline $1859 / 08 / 25$ & Guatemala & $13.0^{\circ} \mathrm{N} 87.5 \mathrm{~W}$ & 6.2 & La Unión \\
\hline $1859 / 12 / 08$ & Guatemala & $13.0^{\circ} \mathrm{N} 89.8 \mathrm{~W}$ & 7.0 & Acajutla \\
\hline $1902 / 02 / 26$ & Guatemala & $13.5^{\circ} \mathrm{N} 89.5 \mathrm{~W}$ & 8.3 & $\begin{array}{l}\text { Acajutla } \\
\text { Barra de Santiago } \\
\text { La Paz }\end{array}$ \\
\hline $1906 / 01 / 31$ & Ecuador & $1.0^{\circ} \mathrm{N} 80.0^{\circ} \mathrm{W}$ & 8.6 & All the coast \\
\hline $1919 / 06 / 29$ & Nicaragua & $13.50^{\circ} \mathrm{N} 87.50^{\circ} \mathrm{W}$ & 6.7 & La Unión \\
\hline $1950 / 10 / 05$ & Costa Rica & $11.0^{\circ} \mathrm{N} 85.0^{\circ} \mathrm{W}$ & 7.7 & $\begin{array}{l}\text { La Libertad } \\
\text { La Unión }\end{array}$ \\
\hline $1950 / 10 / 23$ & Guatemala & $14.3^{\circ} \mathrm{N} 91.7^{\circ} \mathrm{W}$ & 7.1 & La Unión \\
\hline $1952 / 11 / 04$ & Russia & $52.8^{\circ} \mathrm{N} 159.5^{\circ} \mathrm{W}$ & 9.0 & La Libertad \\
\hline $1957 / 03 / 10$ & USA & $51.3^{\circ} \mathrm{N} 175.6^{\circ} \mathrm{W}$ & 8.1 & $\begin{array}{l}\text { Acajutla } \\
\text { La Unión }\end{array}$ \\
\hline $1960 / 05 / 22$ & Chile & $39.5 \mathrm{~S} 74.5^{\circ} \mathrm{W}$ & 9.5 & La Unión \\
\hline $1964 / 03 / 28$ & USA & $61.1^{\circ} \mathrm{N} 147.5^{\circ} \mathrm{W}$ & 9.2 & $\begin{array}{l}\text { Acajutla } \\
\text { La Unión }\end{array}$ \\
\hline 1985/09/19 & Chile & $18.19^{\circ} \mathrm{N} 102.53^{\circ} \mathrm{W}$ & 8.0 & Acajutla \\
\hline 1992/09/01 & Nicaragua & $11.73^{\circ} \mathrm{N} 87.39^{\circ} \mathrm{W}$ & 7.7 & Golfo de Fonseca \\
\hline $2004 / 12 / 26$ & Indonesia & $3.29^{\circ} \mathrm{N} 95.98 \mathrm{E}$ & 9.0 & Acajutla \\
\hline 2012/08/26 & El Salvador & $12.28^{\circ} \mathrm{N} 88.53^{\circ} \mathrm{W}$ & 7.3 & $\begin{array}{l}\text { Bahía de Jiquilisco } \\
\text { (Isla de Mendez) }\end{array}$ \\
\hline
\end{tabular}

such as river and coastal flooding. Ultimately, the number of people to be evacuated, their location, and their characteristics regarding difficulties for evacuation are known.

The analysis of the safe areas has considered both horizontal and vertical shelters. Regarding the horizontal evacuation and based on the potentially flooded area, Fig. 8 shows the proposed security zoning for the Western Coastal Plain of El Salvador, which is composed of (i) the tsunami-flooded area (in blue); (ii) the medium-security area (in yellow), established between the maximum flood level in the study area and a security level specifically determined for this zone (20 m a.s.l.); and (iii) the high-security area (in green) from 

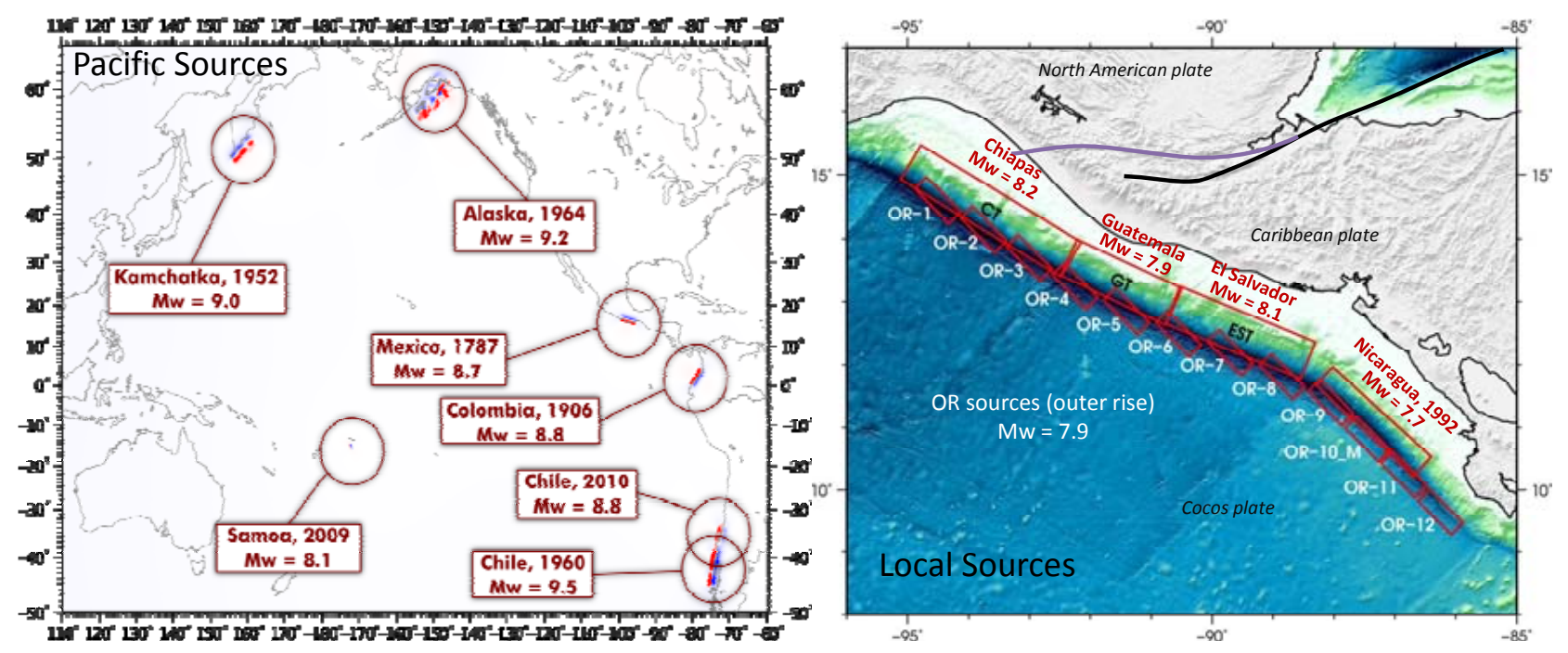

Fig. 5. Tsunamigenic sources aggregated for the deterministic analysis.

this level onwards. Potential vertical shelters located within the different tsunami hazard areas in the three local studies have been identified, analysed and prioritized based on their capacity, safety, and accessibility. In the case of the Western Coastal Plain, analysed here, no vertical shelters were found. The current road network has been analysed, in collaboration with local community leaders through participatory workshops, to identify the existing evacuation routes in the study area, with those roads that connect populated areas with medium-security areas being selected and prioritized in terms of ease of travel and safety. Figure 8 also shows the two specific locations selected in the Western Coastal Plain to be analysed in detail. The results presented in this paper refer to the Barra de Santiago Area (the box outlined on the left).

The Barra de Santiago area, located within Jujutla and San Francisco Menéndez municipalities (Ahuachapán region), is characterized by a $9 \mathrm{~km}$-long sand spit that protects the estuary (Estero El Zapote) of the Aguachapío, Guayapa and El Naranjo rivers. The wetland includes an important mangrove area and belongs to the Complejo Barra de Santiago ANP (Protected Natural Area). According to the census (VI Censo de Población y V de Vivienda, DIGESTYC, 2007) and the hazard modelling results, the number of people located in the tsunami-flooded area is around 3300, $75 \%$ being located on the sand spit (Barra de Santiago canton), which was affected by the tsunami of 1902 (see Table 5) and where, according to the local knowledge, only 5 persons survived the event. Figure 9 shows, for the Barra de Santiago area, (i) the main existing evacuation routes (in purple) and the connecting paths (in red); (ii) the location of all the critical infrastructures which must be considered when planning the evacuation, i.e. critical buildings such as schools, hotels, health centres, etc., together with their capacity, and basic needs supply infrastructures such as wells; and (iii) the number of people by census tract (it must be pointed out here that the populationrelated coloured dots are located exactly in the centroid of each census tract polygon, which represents the location of the coastal communities quite accurately for the small census tracts but not for the big ones, this being the case with the brown-dot census tract whose population is located in the medium-security area, i.e. the yellow area). It is necessary to model and analyse whether the routes allow for the evacuation of people in the time available, or if it is necessary to propose alternative routes.

\subsection{Time calculation}

The tsunami arrival time and the response time calculated for the study area are presented here. A set of tsunami arrival time maps has been generated through numerical modelling, based on a deterministic analysis that combines the 23 worst credible cases of tsunamis that could impact on the Salvadoran coast. This worst credible case correctly corresponds to a tsunami generated by nearby sources due to an earthquake originating in the subduction zone (Cocos Plate-Caribbean Plate) off the coast of El Salvador. Accordingly the tsunami arrival time presented in this paper is related to a locally generated tsunami, representing the most conservative case in terms of evacuation time and, consequently, safety for the population. In the case of a tsunami caused by a more distant source, these times would obviously increase.

Considering this tsunami scenario, Fig. 10 shows the tsunami arrival time for the Western Coastal Plain which varies between 25 and 45 min depending on the zone, with the 25 entire coast of El Salvador being exposed to this time range. The first tsunami wave would arrive in the area of the Barra de Santiago $40 \mathrm{~min}$ after the tsunami generation time. 

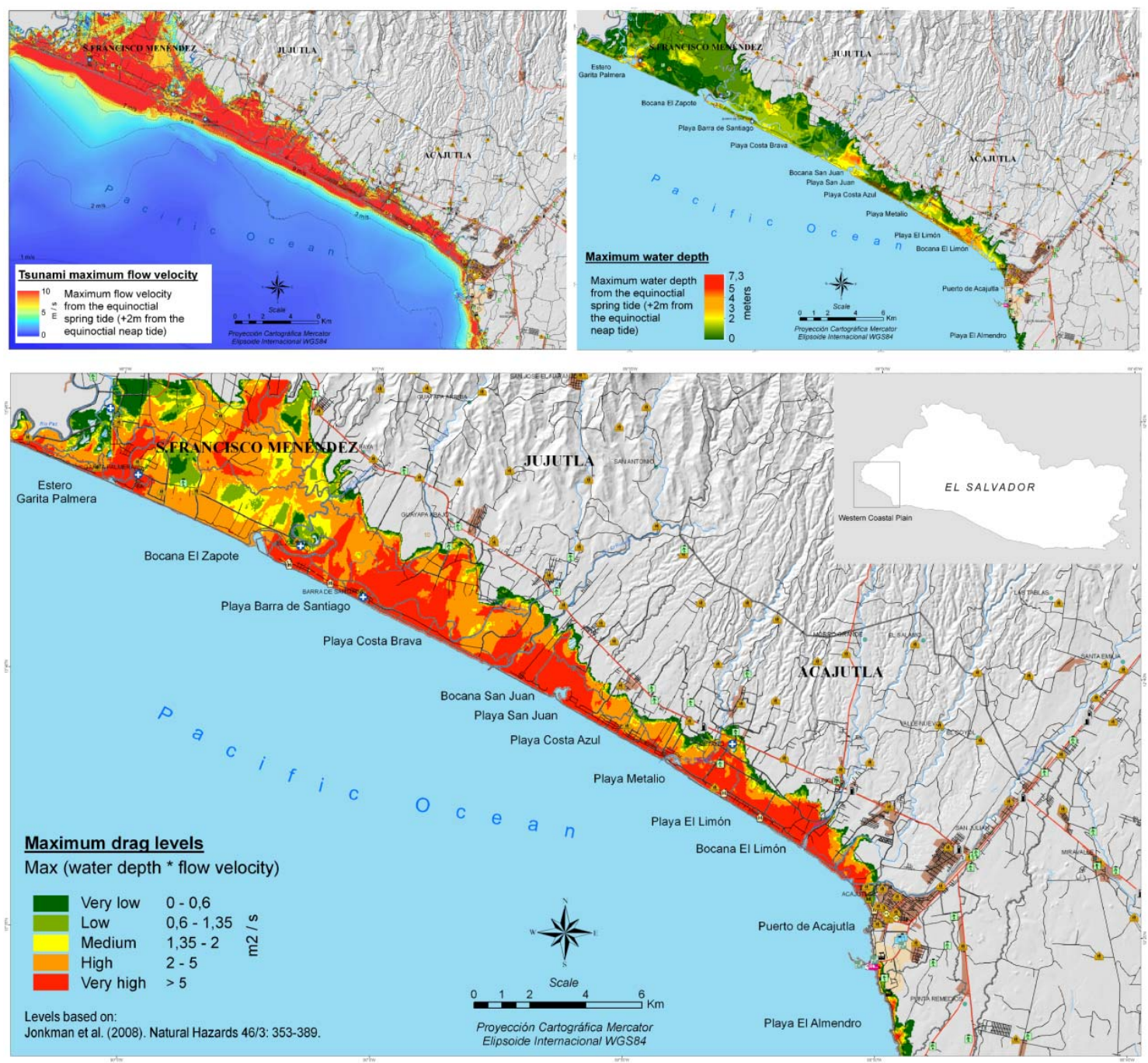

Fig. 6. Hazard maps for the Western Coastal Plain of El Salvador: maximum flow velocity (above left), maximum water depth (above right) and maximum drag (below).

To calculate the response time, several workshops were held with the authorities responsible for the management of different aspects of a tsunami emergency in El Salvador. These workshops allowed for the collection and compilation of the appropriate information and knowledge concerning the approximate duration of the different time intervals involved in this concept:

- The time including (i) the earthquake detection and characterization by the Ministry of Environment and Natural Resources (MARN), (ii) the issuing of the tsunami warning by MARN, (iii) the reception of the alert by the Directorate General of Civil Protection, and (iv) its transmission to the different Civil Protection levels (Departmental, Municipal and Communal Civil Protection committees), takes a total of approximately $13 \mathrm{~min}$.
- Based on experience gained in previous emergency processes for other coastal risks that frequently affect the study area (coastal and river flooding), the time required to transmit the alert to all the people in the community by those responsible in the Communal Civil Protection Committee, is estimated to be $17 \mathrm{~min}$.

- Due to the lack of information regarding the reaction time of the population and recognizing the simplification applied, as there is a strong likelihood that the whole population would not evacuate at the same time, the time elapsed from the moment they are alerted until they begin to evacuate is assumed to be $15 \mathrm{~min}$ according to Post et al. (2009) and Strunz et al. (2011).

In conclusion, the current response time in El Salvador for a tsunami event is therefore approximately $45(13+17+$ 15) min. The next task is to calculate the evacuation time 

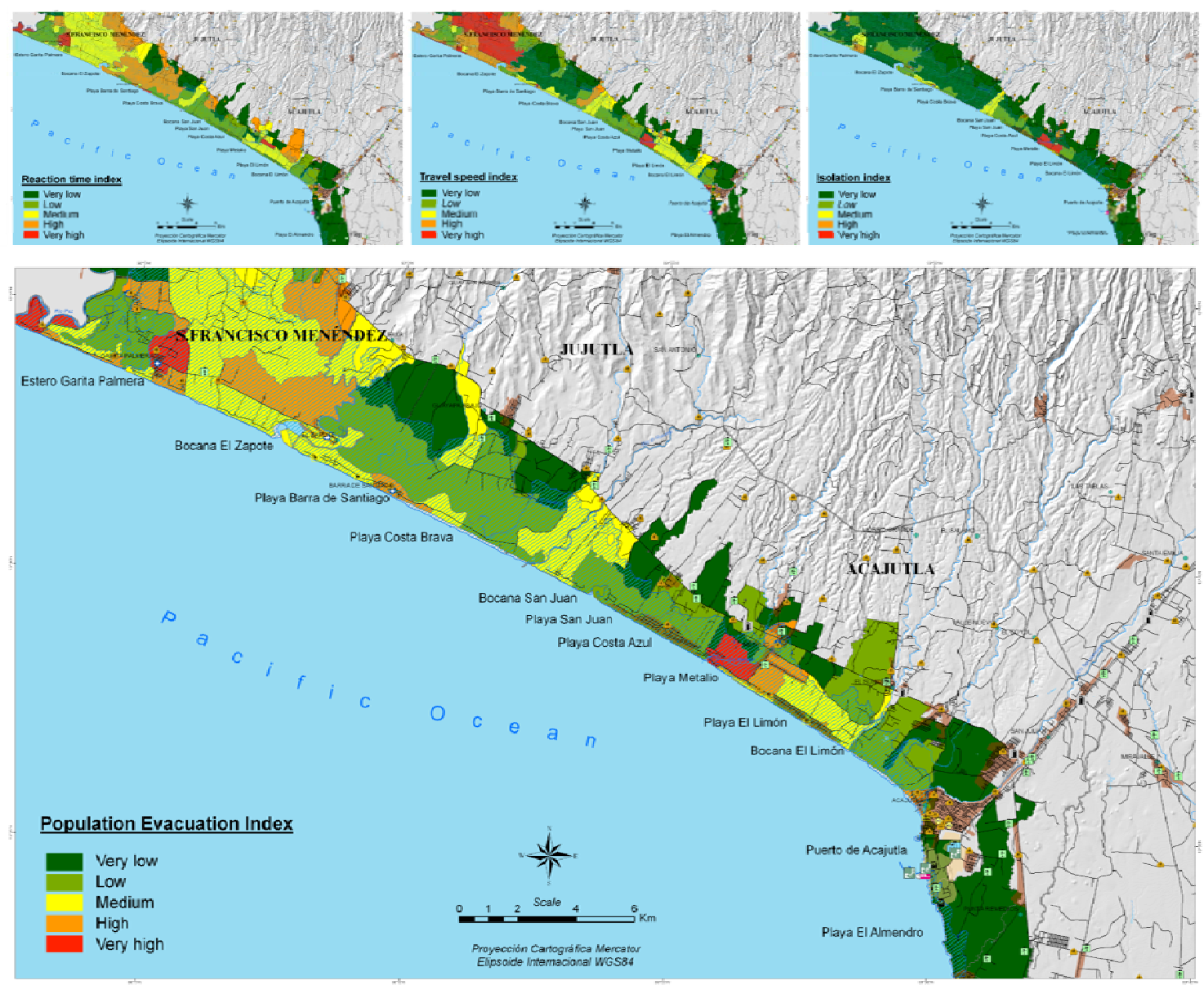

Fig. 7. Population evacuation index (PEI) and related indices: reaction time (above left), travel speed (above centre), isolation (above right) - Western Coastal Plain (El Salvador).

which corresponds to this response time, using evacuation modelling.

\subsection{Evacuation modelling}

Based on the tsunami arrival time, the security zoning and the road network, evacuation modelling allows the identification of the optimal evacuation routes and the time the population needs to evacuate. For this case study, the origin points are located at every road intersection inside the flooded area according to the spatial distribution and number of people by canton/census tracts and the location of critical buildings. Therefore, depending on the existing road intersections, each origin point will represent a variable number of people. Having this information in mind is essential for further steps (evacuation balance, designing of vertical evacuation shelters, etc.).

The evacuation of the population has been modelled for an initial response time of $45 \mathrm{~min}$ (RT45), equivalent to the current response time calculated for El Salvador (Fig. 11). The contour line of $45 \mathrm{~min}$ for the first tsunami wave ar- rival is shown in orange inside the flooded area. It is clear that RT45 means that when the warning arrives in the communities, the tsunami has already reached the coast, and is spreading through the exposed area. The main conclusion obtained from the RT45 results is that most of the exposed population would not be able to evacuate for a response time of $45 \mathrm{~min}$. Results are also presented in pie charts by census tract (Fig. 12), with the green colour representing the percentage of people who evacuate and the red colour representing the percentage who do not; the census tracts showing both options highlight the fact that the evacuation time is also a function of a person's speed (i.e. the fast ones would evacuate, the slow ones would not), and is not only determined by the distance to be travelled in the available time.

\subsection{Proposals of alternatives for critical areas}

Based on the evacuation results obtained (i.e. most of the exposed population would not be able to evacuate for a response time of $45 \mathrm{~min}$ ), the formulation of particular measures to improve the evacuation of the area is necessary. 


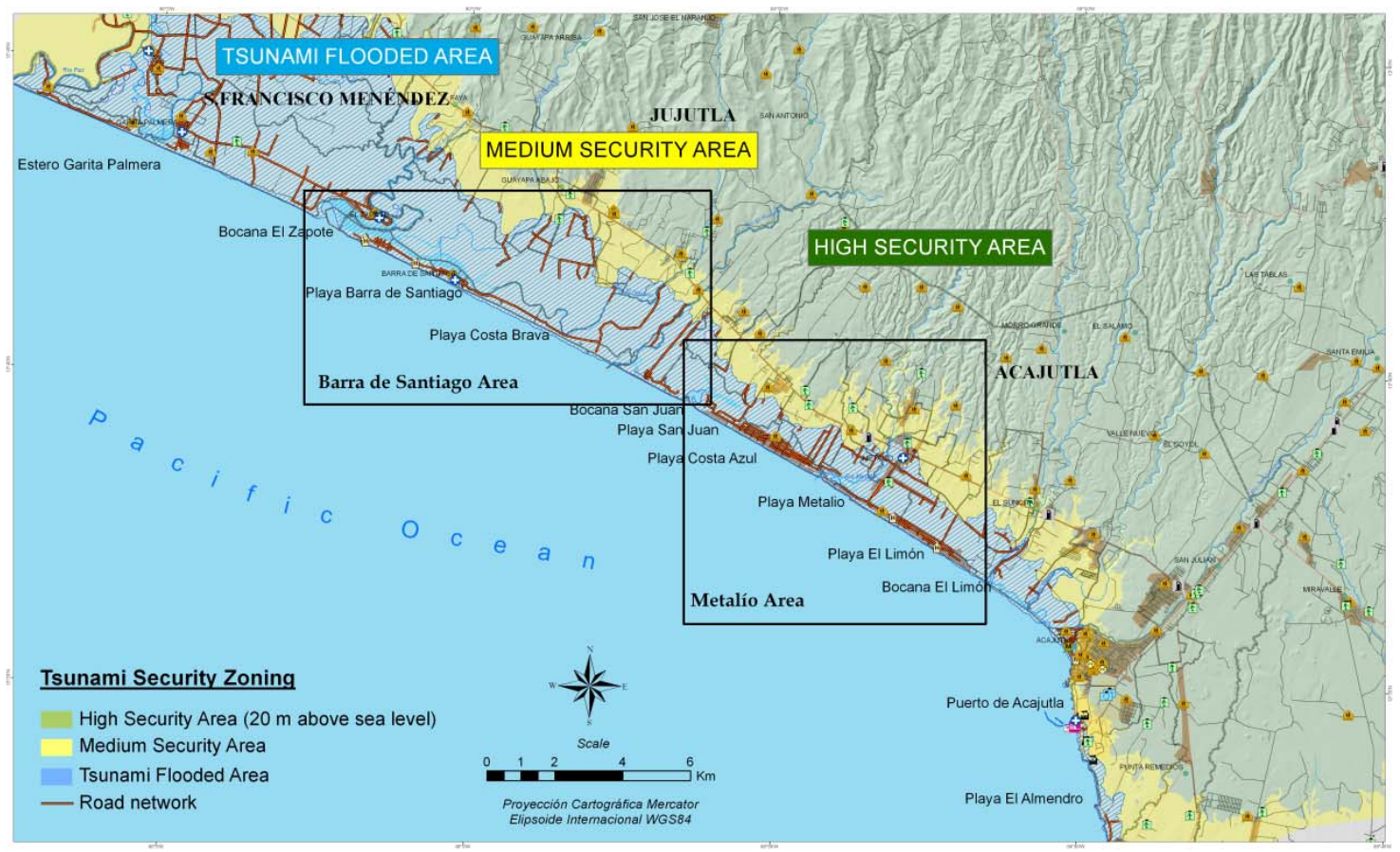

Fig. 8. Tsunami security zoning and existing road network - Western Coastal Plain (El Salvador). Black rectangles show the areas where a detailed analysis has been carried out to identify the evacuation routes, the results for the Barra de Santiago Area being presented in this paper.

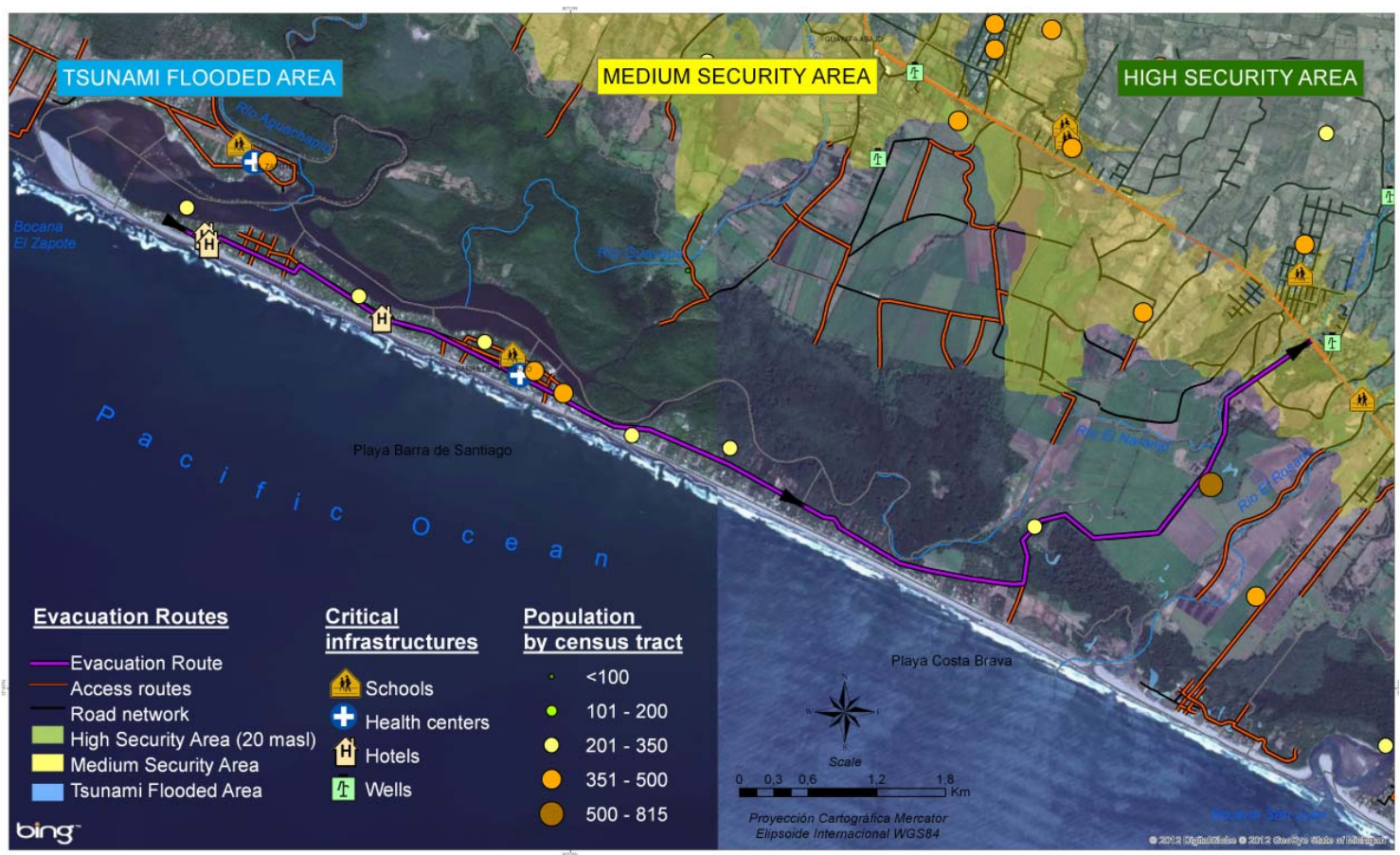

Fig. 9. Existing evacuation routes, critical infrastructures and population by census tract - Barra de Santiago, Western Coastal Plain (El Salvador). 


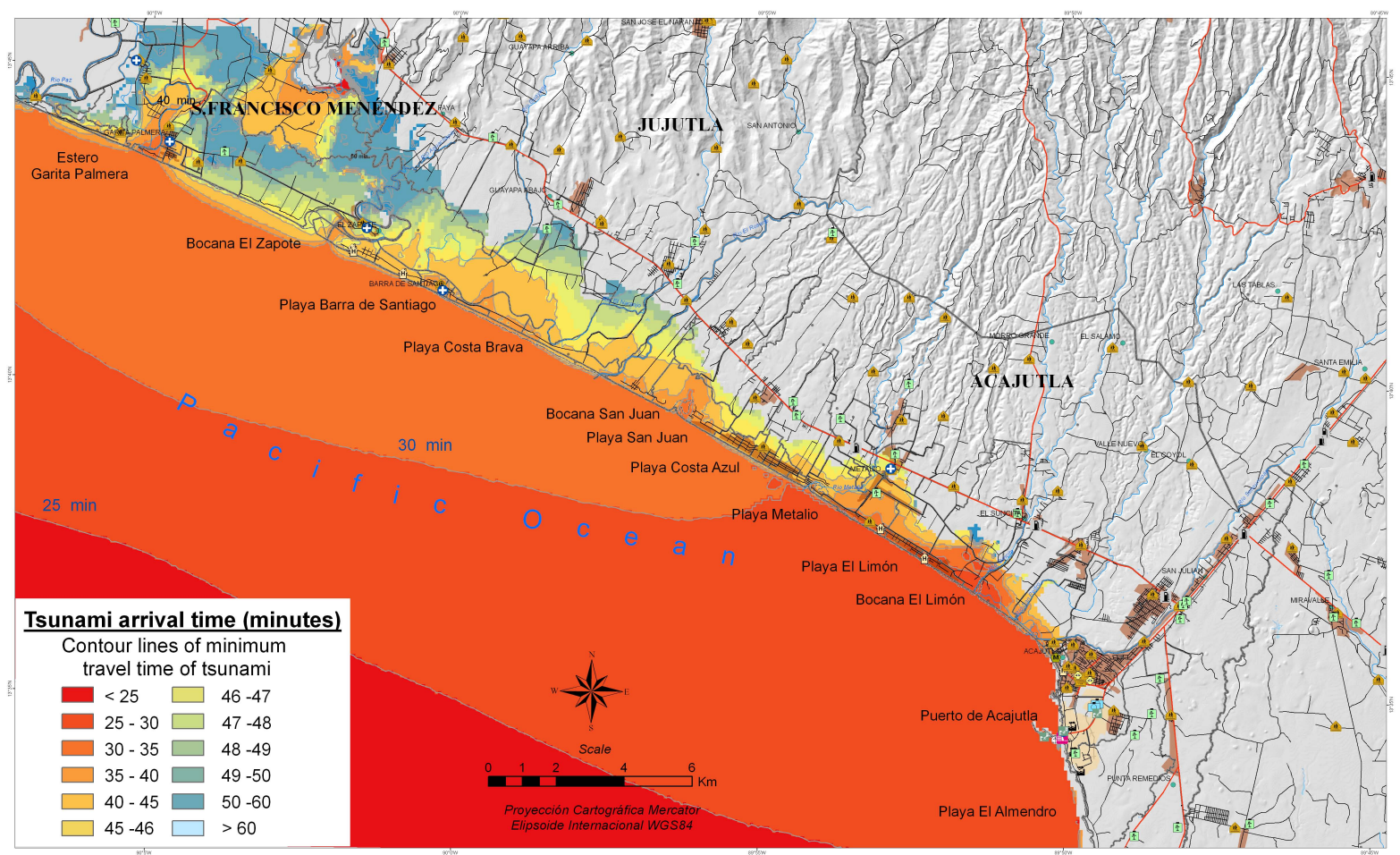

Fig. 10. Tsunami arrival time for the worst-case credible scenario (i.e. aggregated case combining the 23 worst credible cases of tsunami that could impact on the Salvadorian coast) - Western Coastal Plain (El Salvador).

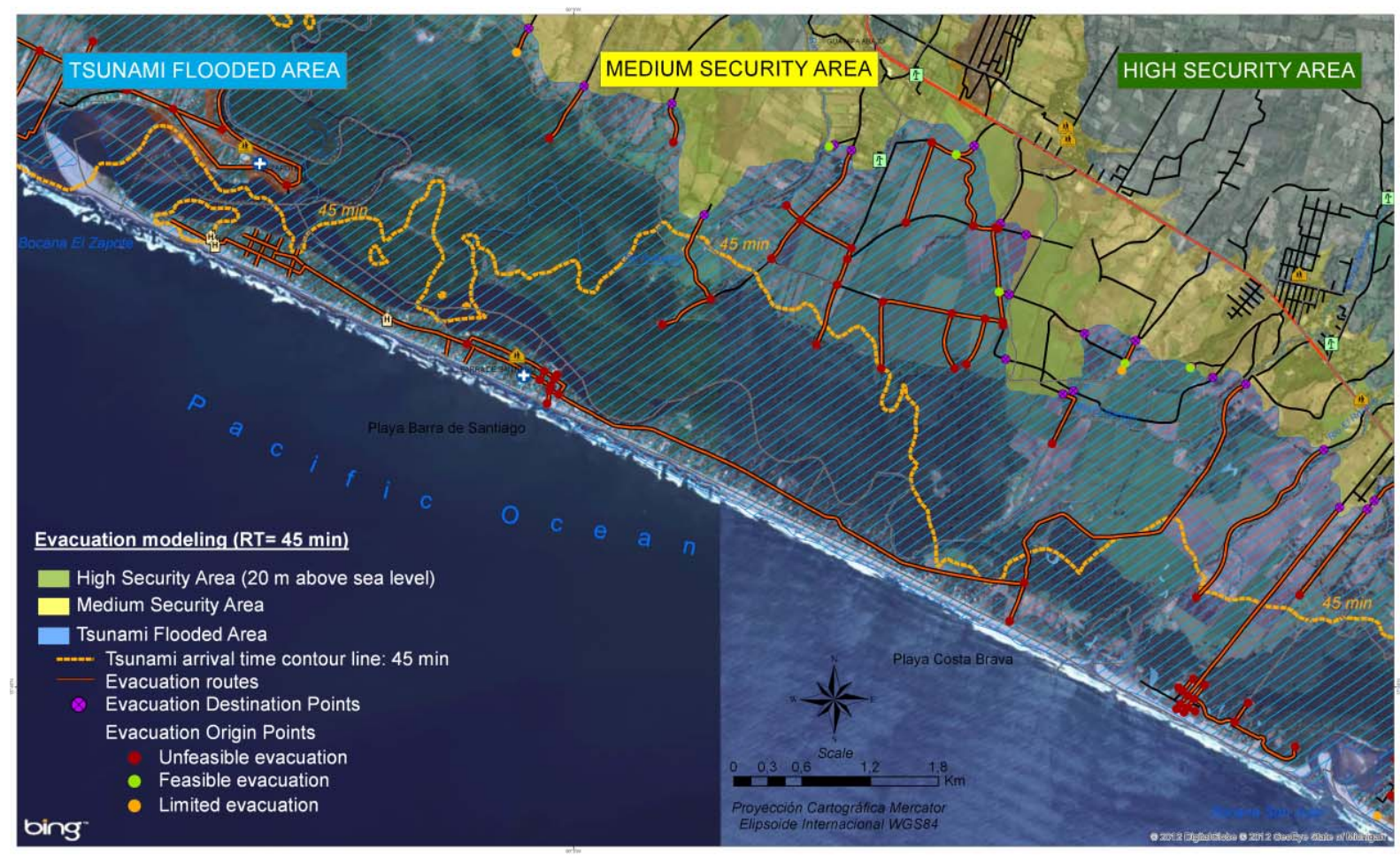

Fig. 11. Evacuation time modelling for a response time of 45 min (RT45) - Barra de Santiago, Western Coastal Plain (El Salvador). 


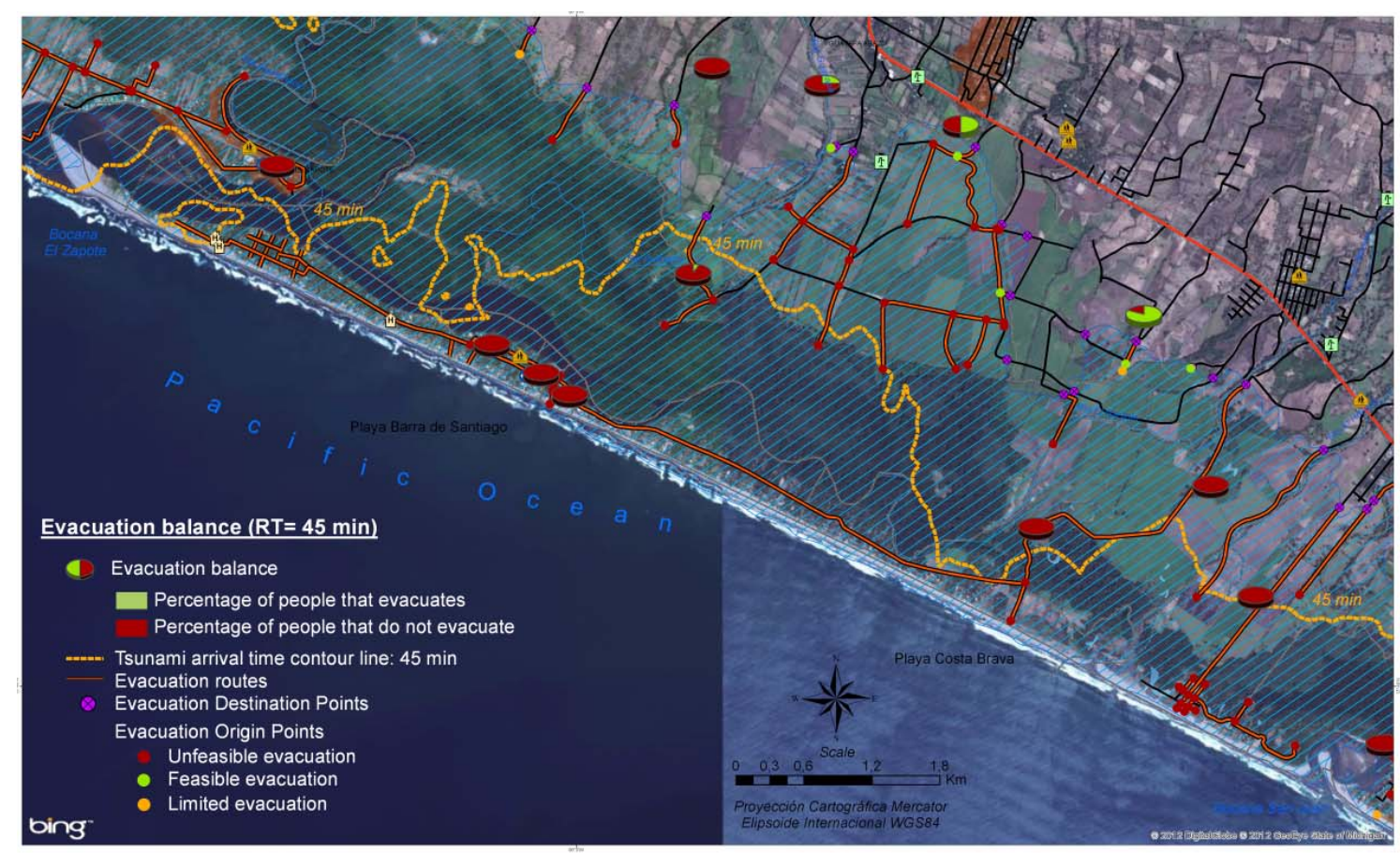

Fig. 12. Evacuation balance for a response time of 45 min (RT45) and by census tract - Barra de Santiago, Western Coastal Plain (El Salvador).

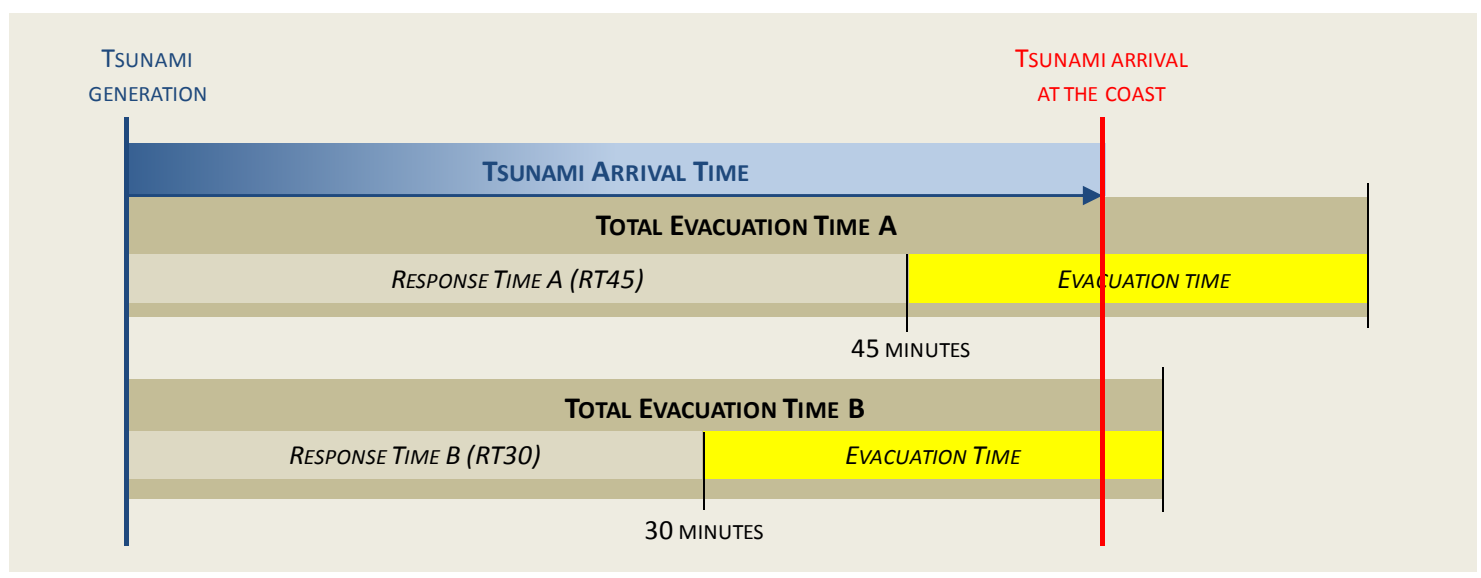

Fig. 13. Response time modelled: 45 and 30 min. The Total Evacuation Time (TET) A considers the current situation in El Salvador (RT45, response time of $45 \mathrm{~min}$ ). The evacuation modelling showed that most of the coastal population would not be able to evacuate. The TET B considers a lower response time (RT30) in order to model and understand if this reduction would be enough to achieve a successful evacuation for the whole coast or if further RT reductions are required.

These measures include (i) the reduction of the response time, and (ii) the reduction of the distance to be travelled by the population. These two proposed measures are then tested using evacuation modelling until it is confirmed that the critical area is eliminated and that the entire area evacuates successfully.

A new modelling has been performed for a response time of $30 \mathrm{~min}$ (RT30) in order to understand the implications, in terms of people affected, of taking less time to (i) detect the tsunami, (ii) warn the people, and (iii) start evacuating, since this situation would then result in increased time being available for evacuation (Fig. 13). The selection of the several response times to model is site-specific and should be adapted to each case study; the example applied to this case (RT30) and presented below does not imply that this is a suitable time threshold for all cases, or even for El Salvador. The idea is to reduce the response time as much as possible, combined with further measures to reduce the distance to be travelled. 


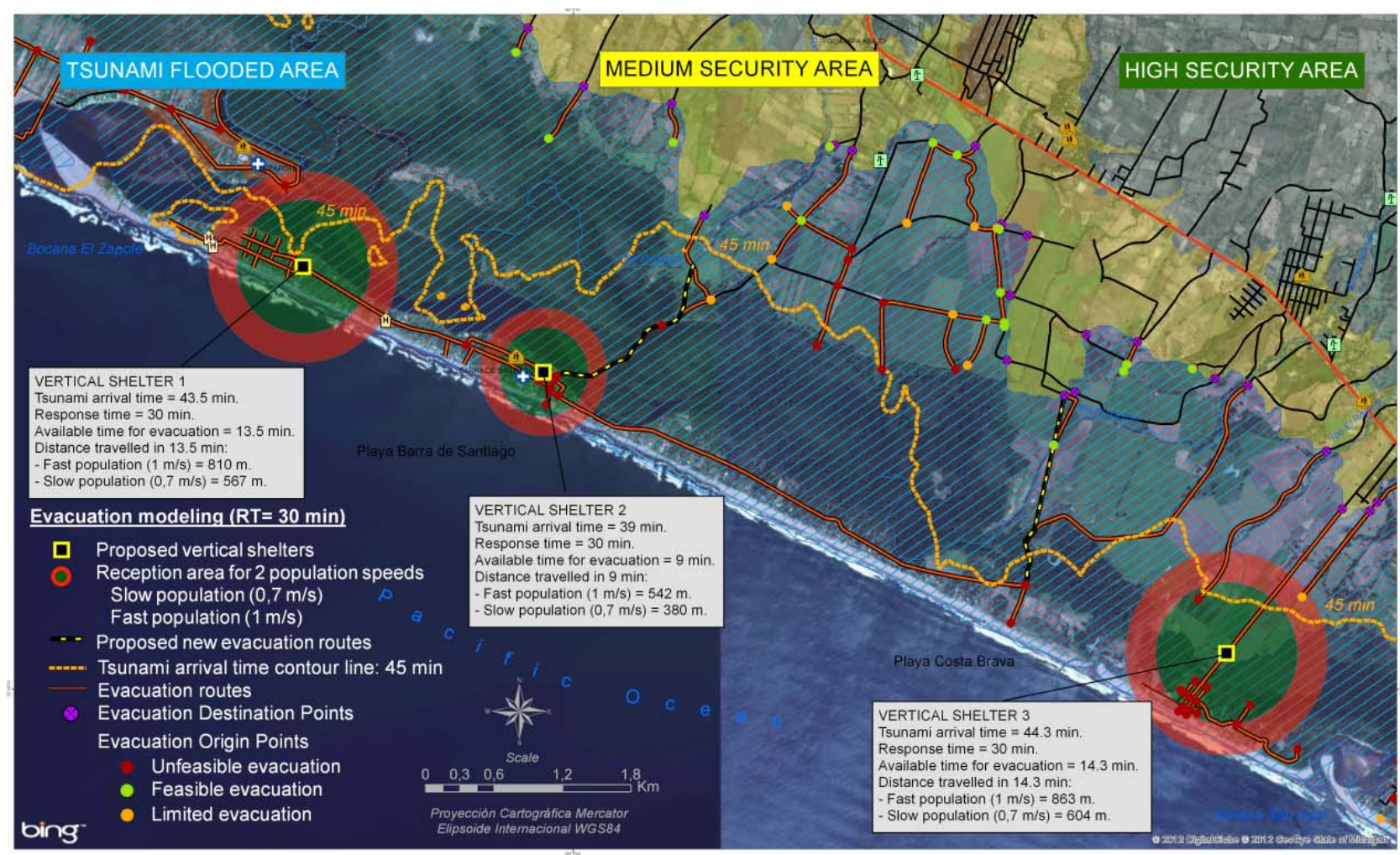

Fig. 14. Evacuation time modelling for a response time of $30 \mathrm{~min}$ (RT30) and proposal of alternatives for critical areas - Barra de Santiago, Western Coastal Plain (El Salvador).

Compared to the evacuation modelling for RT45 (Fig. 11), the modelling for RT30 (Fig. 14) shows that the communities located close to safe areas and above the tsunami arrival time contour line of $45 \mathrm{~min}$, would more or less successfully evacuate for this new response time (origin points changed to green and orange). The communities located below the $45 \mathrm{~min}$ contour line, however, would not evacuate (origin points still in red) even with the 15 additional minutes afforded by RT30.

For these latter communities which would not able to evacuate in time, further measures are proposed, i.e. the reduction of the distance to be travelled by these communities, by means of building vertical evacuation shelters and/or new evacuation routes. These measures are represented in Fig. 14 by yellow-black elements, with squares representing the new vertical shelters, and lines representing the new evacuation routes. As explained in the methodology, the green and red concentric rings surrounding the towers represent the reception distance for both population speeds. Special attention is paid to the critical buildings (1 school, 3 hotels and 1 health centre in Barra de Santiago) in order to have them included in the reception area of the towers. The combination of this information, together with the amount of people to be evacuated, indicates the number of persons that these shelters should be designed to accommodate (in this case, 2500 persons between towers 1 and 2, and 800 in tower 3, approximately).

The iterative modelling of subsequent measures ensures that all the starting evacuation points change to green, indicating the evacuation of the entire exposed population in the time available.

It is important to point out that these analyses and mapping resources are oriented to and designed for risk and emergency managers, in order to provide them with technically sound information to assist in the formulation of optimal evacuation planning for specific areas. The evacuation maps which are to be provided to the exposed local communities, based on the results obtained from the presented framework, must however be simplified to ensure they are intuitive and can be easily understood by the members of the communities.

\section{Conclusions}

Advances in the understanding and prediction of tsunami impacts allow the development of risk reduction strategies for tsunami-prone areas, with evacuation planning being an essential requirement to save lives during emergencies. This paper presents an integral framework for the formulation of tsunami evacuation plans based on tsunami hazard 
and vulnerability assessment and evacuation modelling. This methodology considers (i) the hazard aspects (tsunami flooding characteristics and arrival times), (ii) the characteristics of the exposed area (people, shelters and road network), (iii) the current tsunami warning procedures and timing, (iv) the time needed to evacuate the population, and (v) the identification of measures to improve the evacuation process. The presented framework aims to bridge the gap between science and management in terms of tsunami evacuation and presents evacuation modelling as a vital tool for disaster risk management and evacuation planning. The framework has been applied to the El Salvador case study, demonstrating its applicability to site-specific response times and population characteristics.

The hazard assessment, through the tsunami numerical modelling, permits the generation of different hazard maps (i.e. maximum wave height elevation, maximum water depth, minimum tsunami arrival time, maximum flooding level or "run-up", and maximum drag regarding people instability) which provides knowledge about the exposed area, the locations which would receive higher impacts and the tsunami first wave arrival time, all being critical information for evacuation purposes. The worst case scenario is the most conservative in terms of risk management.

The vulnerability assessment of the exposed population assists in the designing of specificity-oriented measures in order to deal with specific weaknesses in terms of evacuation (see Table 1). Several characteristics of the population have been analysed: (i) the total number of exposed people, (ii) the number of people in critical buildings (schools, hospitals, geriatrics, hotels, etc.), together with illiteracy and intellectual disability, providing information about reaction times; (iii) slow groups (the elderly and children) and physical disability which are directly related to the travel speed; and (iv) badly connected areas which translate into community isolation, impacting both the reception of an alert and the subsequent evacuation. The analysis of the existing road network and safe areas provides knowledge about the current evacuation infrastructure and may highlight the need for repairs and improvements.

The proposed evacuation modelling helps by identifying (i) the shortest routes that people have to travel from their places of origin to destination points, considering the slope and different population speeds, and (ii) the evacuation degree of success for the available evacuation time. This modelling also considers the response time, understood as the time from the tsunami generation until the population begins to evacuate: (i) the current emergency protocols and the experience of the responsible authorities both provide essential information about the time needed for tsunami detection, issuing of warnings, alert transmission and reception, all of which are extremely important for the population, as a shorter response time directly translates into longer time available for the population to evacuate; (ii) the population reaction time is assumed to be $15 \mathrm{~min}$ (Post et al., 2009;
Strunz et al., 2011). It is important to mention that the proposed framework permits the application of more complex evacuation models as required and/or further research advances such as those regarding the slope calculation or the optimization process for shelter location. Modelling the current response time gives the real evacuation situation, which is the starting point for risk management. The evacuation degree of success obtained for the current response time helps in defining alternatives for those communities that do not have options to evacuate in the current situation, by means of reducing the response time and/or shortening the distances to be travelled (through additional routes and/or shelters). This sensitivity analysis of the evacuation model represents a powerful tool for managers to reduce the risk in specific areas, by ensuring the successful evacuation of the population, as it allows predicting the results of specific management options.

A method for the identification of possible locations for vertical evacuation shelters is proposed, providing useful information for each shelter, such as the tsunami arrival time, the response time, the time available to evacuate, and the reception distance for both population speeds. The combination of this information with the amount of people to be evacuated indicates the capacity that these shelters should accommodate.

Finally, the proposed framework permits the organization, classification and prioritization of the gathered information, in order to better define the several risk management measures to be included in an evacuation plan.

Regarding some of the results obtained for El Salvador, the evacuation modelling for the current response time of 45 min (RT45; i.e. warning time $30 \mathrm{~min}$, reaction time $15 \mathrm{~min}$ ) highlighted that improvements to the warning process must be made to ensure the success of the evacuation, as most of the coastal communities would be reached by the tsunami before being warned about it. A reduction of $15 \mathrm{~min}$ in the response time (RT30) showed that a higher percentage of populations evacuates (proving the importance of working on this issue); however, the communities located closer to the coastline would not be able to reach the safe areas. For these communities an attempt to identify alternative measures to ensure their evacuation is proposed, such as building new evacuation routes and new vertical shelters. These combined measures (reducing response time and reducing distances to travel) have been demonstrated to be useful for achieving the desired results. The repetition of the evacuation modelling for each group of measures proposed ensures the control and reduction of critical areas. 
Acknowledgements. We would like to thank the Spanish Agency for International Development Cooperation (AECID) for funding and supporting the project framing this research, named "Evaluación del Riesgo por tsunami en la costa de El Salvador (Fase I: Peligrosidad, Fase II: Vulnerabilidad y Riesgo)" and developed during the period 2009-2012; and the Ministry of Environment and Natural Resources (MARN) of El Salvador for our fruitful collaboration. We also thank the European projects NEARToWARN (Near-field Tsunami Warning) and ASTARTE (Assessment, STrategy And Risk Reduction for Tsunamis in Europe) for funding the first three authors' research, and Roberto Minguez (IH Cantabria) for his guidance on optimization procedures.

Edited by: I. Didenkulova

Reviewed by: two anonymous referees

\section{References}

Aboelata, M. and Bowles, D. S.: LIFESim: A Model for Estimating Dam Failure Life Loss, Draft Report to Institute for Water Resources, US Army Corps of Engineers and Australian National Committee on Large Dams, Institute for Dam Safety Risk Management, Utah State University, Logan, Utah, available at: http://uwrl.usu.edu/people/faculty/bowles. html\#lifelossestimation (last access: 11 November 2013), 2005.

Álvarez-Gómez, J. A., Gutiérrez-Gutiérrez, O. Q., Aniel-Quiroga, I., and González, M.: Tsunamigenic potential of outer-rise normal faults at the Middle America trench in Central America, Tectonophysics, 574/575, 133-143, 2012.

Álvarez-Gómez, J. A., Aniel-Quiroga, Í., Gutiérrez-Gutiérrez, O. Q., Larreynaga, J., González, M., Castro, M., Gavidia, F., Aguirre-Ayerbe, I., González-Riancho, P., and Carreño, E.: Tsunami hazard assessment in El Salvador, Central America, from seismic sources through flooding numerical models., Nat. Hazards Earth Syst. Sci., 13, 2927-2939, doi:10.5194/nhess-132927-2013, 2013.

Alvear Brito, J. G. and Cruz D’Howitt, M. A.: Elaboración de un mapa de accesibilidad y modelo de evacuación ante una eventual ocurrencia de tsunami en las ciudades de Salinas y Bahía de Caráquez, mediante herramientas geoinformáticas, Revista Geoespacial, 5, 1-15, 2009 (in Spanish).

BC Hydro: BC Hydro Life Safety Model - Formal Description, Engineering Report E299, October 2004. available at: http://www. lifesafetymodel.net/publications.html (last access: 11 November 2013), 2005.

Cano, V. H.: Application in GIS for the generation of evacuation routes, tools for urban planning: "Case: East Coast of Maracaibo Lake”, Rev. Fac. Ing. UCV. Editorial Innovación Tecnológica (EdIT), de la Facultad de Ingeniería de la Universidad Central de Venezuela, Caracas, 26, 17-26, available at: http://saber.ucv.ve/ ojs/index.php/rev_fiucv/article/view/4955/4763 (last access: 11 November 2013), 2011.

Clerveaux, V. and Katada, T.: Tsunami scenario simulator: a tool for ensuring effective disaster management and coastal evacuation in a multilanguage society, Sci. Tsunami Hazards, 27, 48-71, 2008.

DIGESTYC (Dirección General de Estadística y Censos): VI Censo de Población y V De Vivienda, DIGESTYC, Ministerio de Economía (MINEC) de El Salvador, available at: http://www. censos.gob.sv/ (last access: 11 November 2013), 2007 (in Spanish).

Fernández, M.: Daños, efectos y amenaza de tsunamis en América Central, Rev. Geológ. Am. Cent., 26, 71-83, 2002 (in Spanish).

Fernández, M., Molina, E., Havskov, J., and Atakan, K.: Tsunamis and tsunami hazards in Central America, Natural Hazards, 22, 91-116, 2000.

Fernández, M., Ortiz-Figueroa, M., and Mora, R.: Tsunami hazards in El Salvador, Geolog. Soc. Am., 375, 435-444. 2004.

Garside, R., Johnston, D., Saunders, W., and Leonard, G.: Planning for tsunami evacuations: the case of the Marine Education Centre, Wellington, New Zealand, Austr. J. Emerg. Manag., 24, 1-4, 2009.

González, M., González-Riancho, P., Gutiérrez, O. Q., GarcíaAguilar, O., Aniel-Quiroga, I., Aguirre, I., Álvarez, J. A., Gavidia, F., Jaimes, I., and Larreynaga, J. A.: Tsunami Hazard and Risk Assessment in El Salvador, European Geosciences Union (EGU) General Assembly 2012, Vienna (Austria), 22-27 April 2012.

González-Riancho, P., Aguirre-Ayerbe, I., García-Aguilar, O., Medina, R., González, M., Aniel-Quiroga, I., Gutiérrez, O. Q., Álvarez-Gómez, J. A., Larreynaga, J., and Gavidia, F.: Integrated tsunami vulnerability and risk assessment: application to the coastal area of El Salvador, Nat. Hazards Earth Syst. Sci. Discuss., 1, 2883-2943, doi:10.5194/nhessd-1-2883-2013, 2013.

HR Wallingford: Review of evacuation rescue methods and models, FLOODsite Project, Report Number T17-07-04, published online, available at: http://www.floodsite.net/html/cd_task17-19/ review_evac_models.html (last access: 11 November 2013), 2006.

IH Cantabria-MARN: Instituto de Hidráulica Ambiental IH Cantabria, Ministerio de Medio Ambiente y Recursos Naturales de El Salvador MARN: Catálogo de Vulnerabilidad y Riesgo debido a la inundación por Tsunami en la costa de El Salvador, Spanish Agency for International Development Cooperation (AECID), available at: http://www.ihcantabria.com/es/ proyectos-id/item/843-tsunami-vulnerability-risk-el-salvador (last access: 7 October 2013), 2012 (in Spanish).

Jenks, G. F.: The Data Model Concept in Statistical Mapping, International Yearbook of Cartography, 7, 186-190, 1967.

Jonkman, S. N., Vrijling, J. K., and Vrouwenvelder, A. C. W. M.: Methods for the estimation of loss of life due to floods: a literature review and a proposal for a new method, Nat. Hazards, 46, 353-389, doi:10.1007/s11069-008-9227-5, 2008a.

Jonkman, S. N., Kok, M., and Vrijling, J. K.: Flood risk assessment in the Netherlands: a case study for dike ring South Holland, Risk Anal., 28, 1357-74, doi:10.1111/j.15396924.2008.01103.x, 2008b.

Kolen, B., Maaskant, B., Helsloot, I., and Thonus, B.: EvacuAid: a probabilistic evacuation model to determine the expected loss of life for different mass evacuation strategies, in: Proceedings of the International Conference on Emergency Preparedness: The Challenges of Mass Evacuation, edited by: Albores, P., Aston CRISIS Centre, Aston Business School, Aston University, Birmingham, UK, 21-23 September 2010, 33-43, 2010.

Koshimura, S., Katada, T., Mofjeld, H. O., and Kawata, Y.: A method for estimating casualties due to the tsunami inundation flow, Nat. Hazards, 39, 265-274, doi:10.1007/s11069-006-0027$5,2006$. 
Laghi, M., Cavalletti, A., and Polo, P.: Coastal risk analysis of tsunamis and environmental remediation, Asian Disaster Preparedness Center, Klong Luang, Thailand, 98 pp., 2006.

MARN (Ministerio de Medio Ambiente y Recursos Naturales de El Salvador): Historia de los tsunamis en El Salvador, vulnerabilidad de la costa salvadoreña y actuación del servicio oceanográfico nacional ante esta amenaza, MARN, Dirección General del Servicio Nacional de Estudios Territoriales, Servicio Oceanográfico Nacional, available at: http://www.snet.gob.sv/ver/oceanografia/seccion+educativa/ tsunamis+en+underline+el+salvador (last access: 11 November 2013), 2009 (in Spanish).

Mück, M.: Tsunami Evacuation Modelling, Development and application of a spatial information system supporting tsunami evacuation planning in South-West Bali, Diploma Degree Thesis, University of Regensburg, Bavaria, Germany, 2008.

OECD (Organization for Economic Co-operation and Development)/EC-JRC (European Commission Joint Research Centre): Handbook on Constructing Composite Indicators, Methodology and users guide, OECD Publications, Paris, ISBN 978-92-64-04345-9, available at: http://www.oecd.org/general/searchresults (last access: 11 November 2013), 2008.

Post, J., Wegscheider, S., Mück, M., Zosseder, K., Kiefl, R., Steinmetz, T., and Strunz, G.: Assessment of human immediate response capability related to tsunami threats in Indonesia at a sub-national scale, Nat. Hazards Earth Syst. Sci., 9, 1075-1086, doi:10.5194/nhess-9-10 1075-2009, 2009.

Sato, H., Murakami, H., Kozuki, Y., and Yamamoto, N.: Study on a Simplified Method of Tsunami Risk Assessment, Nat. Hazards, 29, 325-340, doi:10.1023/A:1024732204299, 2003.
Scheer, S., Gardi, A., Guillande, R., Eftichidis, G., Varela, V., and de Vanssay, B.: Handbook of Tsunami Evacuation Planning, SCHEMA (Scenarios for Hazard induced Emergencies Management) Project, published online, available at: http://publications. jrc.ec.europa.eu/repository/handle/111111111/15978 (last access: 11 November 2013), 2011a.

Scheer, S., Guillande, R., and Gardi, A.: Optimizing Tsunami Evacuation Plans Through the Use of Damage Scenarios, Earthzine's [online] Articles, Disaster Management theme, available at: http://www.earthzine.org (last access: 17 May 2013), 2011 b.

Strunz, G., Post, J., Zosseder, K., Wegscheider, S., Muck, M., Riedlinger, T., Mehl, H., Dech, S., Birkmann, J., Gebert, N., Harjono, H., Anwar, H. Z., Sumaryono, Khomarudin, R. M., and Muhari, A.: Tsunami risk assessment in Indonesia, Nat. Hazards Earth Syst. Sci., 11, 67-82, doi:10.5194/nhess-11-67-2011, 2011.

Sugimoto, T., Murakami, H., Kozuki, Y., and Nishikawa, K.: A human damage prediction method for tsunami disasters incorporating evacuation activities, Nat. Hazards, 29, 585-600, 2003.

Tinti, S., Tonini, R., Bressan, L., Armigliato, A., Gardi, A., Guillande, R., Valencia, N., and Scheer, S.: Handbook of Tsunami Hazard and Damage Scenarios, SCHEMA project (Scenarios for Hazard induced Emergencies Management), European Commission's Joint Research Centre, Institute for the Protection and Security of the Citizen, EU Publications Office, Luxembourg, ISBN 978-92-79-19062-9, available at: http://publications.jrc.ec. europa.eu/repository/handle/111111111/16149 (last access: 11 November 2013), 2011.

van Zuilekom, K. M., van Maarseveen, M. F. A. M., and van der Doef, M. R.: A Decision Support System for preventive evacuation of people, in: Geo-information for disaster management, edited by: Zlatanova, P., Van Oosterom, S., and Fendel, E. M., Springer Berlin Heidelberg, Berlin, Heidelberg, 229-253, 2005. 